\title{
KCa1.1 and Kv1.3 channels regulate the interactions between fibroblast-like synoviocytes and T lymphocytes during rheumatoid arthritis
}

Mark R. Tanner ${ }^{1,2}$, Michael W. Pennington ${ }^{3,4}$, Satendra S. Chauhan ${ }^{3}$, Teresina Laragione ${ }^{5}$, Pércio S. Gulko ${ }^{5}$ and Christine Beeton ${ }^{1,6^{*}}$ (D)

\begin{abstract}
Background: Fibroblast-like synoviocytes (FLS) and CCR7 ${ }^{-}$effector memory $T\left(T_{E M}\right)$ cells are two of the major cell types implicated in the progression of rheumatoid arthritis (RA). In particular, FLS become highly invasive, whereas $T_{E M}$ cells proliferate and secrete proinflammatory cytokines, during RA. FLS and T cells may also interact and influence each other's phenotypes. Inhibition of the pathogenic phenotypes of both FLS and TEM cells can be accomplished by selectively blocking the predominant potassium channels that they upregulate during RA: KCa1.1 (BK, Slo1, MaxiK, KCNMA1) upregulated by FLS and Kv1.3 (KCNA3) upregulated by activated TEM cells. In this study, we investigated the roles of KCa1.1 and KV1.3 in regulating the interactions between FLS and TEM cells and determined if combination therapies of KCa1.1- and Kv1.3-selective blockers are more efficacious than monotherapies in ameliorating disease in rat models of RA.
\end{abstract}

Methods: We used in vitro functional assays to assess the effects of selective KCa1.1 and Kv1.3 channel inhibitors on the interactions of FLS isolated from rats with collagen-induced arthritis (CIA) with syngeneic $T_{E M}$ cells. We also used flow cytometric analyses to determine the effects of KCa1.1 blockers on the expression of proteins used for antigen presentation on CIA-FLS. Finally, we used the CIA and pristane-induced arthritis models to determine the efficacy of combinatorial therapies of KCa1.1 and Kv1.3 blockers in reducing disease severity compared with monotherapies.

Results: We show that the interactions of FLS from rats with CIA and of rat $T_{E M}$ cells are regulated by KCa1.1 and KV1.3. Inhibiting KCa1.1 on FLS reduces the ability of FLS to stimulate $T_{E M}$ cell proliferation and migration, and inhibiting KV1.3 on TEM cells reduces $T_{E M}$ cells' ability to enhance FLS expression of KCa1.1 and major histocompatibility complex class II protein, as well as stimulates their invasion. Furthermore, we show that combination therapies of selective KCa1.1 and Kv1.3 blockers are more efficacious than monotherapies at reducing signs of disease in two rat models of RA.

Conclusions: Our results demonstrate the importance of KCa1.1 and KV1.3 in regulating FLS and $T_{E M}$ cells during RA, as well as the value of combined therapies targeting both of these cell types to treat RA.

Keywords: Synovial fibroblast, Immunomodulation, Cell interactions, Dual therapy, Autoimmunity

\footnotetext{
* Correspondence: beeton@bcm.edu

${ }^{1}$ Department of Molecular Physiology and Biophysics, Baylor College of Medicine, One Baylor Plaza, Houston, TX 77030, USA

${ }^{6}$ Biology of Inflammation Center, Center for Drug Discovery, Cardiovascular Research Institute, and Dan L Duncan Comprehensive Cancer Center, Baylor College of Medicine, Houston, TX, USA

Full list of author information is available at the end of the article
}

(c) The Author(s). 2019 Open Access This article is distributed under the terms of the Creative Commons Attribution 4.0 International License (http://creativecommons.org/licenses/by/4.0/), which permits unrestricted use, distribution, and reproduction in any medium, provided you give appropriate credit to the original author(s) and the source, provide a link to the Creative Commons license, and indicate if changes were made. The Creative Commons Public Domain Dedication waiver (http://creativecommons.org/publicdomain/zero/1.0/) applies to the data made available in this article, unless otherwise stated. 


\section{Background}

Rheumatoid arthritis (RA) is a chronic autoimmune disease featuring inflammation centralized within the synovial joints $[1,2]$. Despite major advances in treatment strategies for RA, remission remains uncommon and is achieved in only a subset of patients [3]. Current treatments also render patients immunosuppressed and at increased risk for infections [4]. Therefore, there is an unmet need for novel and innovative strategies to treat this disease without further immunosuppressing patients. T cells have a role in disease pathogenesis; in particular, $\mathrm{CD}^{+} \mathrm{CD}^{+} 5 \mathrm{RA}^{-} \mathrm{CCR} 7^{-}$effector memory $\mathrm{T}$ lymphocytes ( $\mathrm{T}_{\mathrm{EM}}$ cells) are a primary effector $\mathrm{T}$ cell population responsible for the inflammatory aspect of this disease, with characteristic phenotypes of being highly proliferative and the secretion of proinflammatory cytokines within the synovium, leading to joint inflammation [5-7]. Following activation, $\mathrm{T}_{\mathrm{EM}}$ cells upregulate the potassium channel Kv1.3 at their plasma membrane, as opposed to naïve and central memory $\mathrm{T}$ cells, which primarily express the KCa3.1 potassium channel [6-8]. Selective blockade of Kv1.3 reduces $\mathrm{T}_{\mathrm{EM}}$ cell proliferation and cytokine secretion while leaving naïve and central memory $\mathrm{T}$ cells able to become activated. Kv1.3-selective blockers are effective at reducing disease severity in multiple animal models of autoimmunity, including in the pristane-induced arthritis (PIA) model of RA, without affecting the clearance of acute infections $[6,7,9,10]$. As such, Kv1.3 blockers have emerged as promising therapeutics for the treatment of RA [6, 7, 9, 11]. Indeed, ShK-186 (Dalazatide; Kv1.3 Therapeutics, Inc., Seattle, WA, USA), an analog of a venom peptide from the sea anemone Stichodactyla helianthus, is a highly potent and selective Kv1.3 blocker that has shown promise in early clinical trials for the treatment of $\mathrm{T}_{\mathrm{EM}}$ cell-mediated autoimmune disease $[12,13]$. As promising Kv1.3 blockade is as an RA therapy, in experimental models of autoimmunity, ShK-186-treated animals still exhibit signs of joint damage, albeit at significantly lower levels than in control vehicle-treated animals [6,9]. It is likely that other cell types involved in the pathogenesis of RA and its animal models that do not express Kv1.3 are still active following Kv1.3 block and continue to cause disease progression.

Fibroblast-like synoviocytes (FLS) are resident synovial joint cells that develop a highly invasive phenotype during RA, contributing to joint damage, and secrete a variety of proinflammatory cytokines and chemokines [14, 15]. We have previously demonstrated that FLS from patients with RA and from animal models of RA upregulate the potassium channel $\mathrm{KCa} 1.1$ at their plasma membrane [16-20]. KCa1.1 blockade with selective inhibitors, such as the fungal alkaloid paxilline and the Buthus tamulus scorpion venom toxin iberiotoxin
(IbTX), reduces FLS invasion and cytokine and chemokine secretion ex vivo [17, 19, 21]. Furthermore, KCa1.1 blockers reduce disease severity in animal models of RA $[17,21]$. However, similar to what is observed in animal models of autoimmunity treated with Kv1.3 blockers, rats with a model of RA treated with a KCa1.1 blocker still exhibit signs of disease, but at lower levels than vehicle-treated animals $[17,21]$.

FLS and T cells interact within ex vivo settings in which, when stimulated with interferon (IFN)- $\gamma$, FLS express major histocompatibility complex (MHC) class II molecules along with the costimulatory molecule B7-H3 (CD276), intercellular adhesion molecule (ICAM)-1 (CD54), and CD40, allowing FLS to serve as antigen-presenting cells to CD4 ${ }^{+}$ $\mathrm{T}$ cells [22-27]. $\mathrm{T}_{\mathrm{EM}}$ cells also secrete a variety of cytokines, including tumor necrosis factor (TNF)- $\alpha$, interleukin (IL)-17, and IFN- $\gamma$, that are known to induce or enhance the highly invasive, pathogenic phenotype of FLS [28-30]. Therefore, it is likely that FLS and $\mathrm{T}_{\mathrm{EM}}$ cells interact during RA to increase each other's pathogenic features. It may be possible to reduce these interactions through modulating the predominant potassium channels each cell expresses. Importantly, FLS do not express Kv1.3, and the Kv1.3 blocker ShK-186 does not inhibit the RA-FLS pathogenic phenotype, because ShK-186 does not block KCa1.1 channels [19, 31, 32]. Likewise, no T cell populations are known to express $\mathrm{KCa} 1.1$, and the $\mathrm{KCa} 1.1$ blockers paxilline and IbTX do not block Kv1.3, the potassium channel predominantly expressed by $\mathrm{T}_{\mathrm{EM}}$ cells [7, 33, 34].

In this study, we show that $\mathrm{KCa} 1.1$ is a regulator of MHC class II molecule expression in FLS from the collagen-induced arthritis (CIA) model of RA. KCa1.1 block reduces the CIA-FLS ability to stimulate the proliferation and migration of $\mathrm{T}_{\mathrm{EM}}$ cells. We further show that blocking Kv1.3 reduces $\mathrm{T}_{\mathrm{EM}}$ cells' ability to induce the invasion of CIA-FLS and induce an increase in expression of $\mathrm{KCa} 1.1$ and $\mathrm{MHC}$ class II molecules on CIA-FLS. Finally, we show that a combined therapy of potassium channel blockers targeting both $\mathrm{KCa} 1.1$ and Kv1.3 is more effective than monotherapies at reducing disease severity in two rat models of RA. Our studies highlight the importance of KCa1.1 on FLS and Kv1.3 on $\mathrm{T}_{\mathrm{EM}}$ cells as moderators of disease severity in RA, and they further validate the use of selective, potent potassium channel blockers as novel therapies for RA.

\section{Methods}

\section{Animals}

All experiments involving rats were approved by the Institutional Animal Care and Use Committee at Baylor College of Medicine. Female Lewis rats (8-11 weeks old; Charles River Laboratories, Wilmington, MA, USA) and female Dark Agouti rats (8-11 weeks old; Envigo, Indianapolis, IN, USA) were housed in autoclaved setups 
in an Association for Assessment and Accreditation of Laboratory Animal Care International-accredited facility in which they were provided food and water ad libitum.

\section{Isolation and culture of FLS}

FLS from patients with RA, as defined by criteria of the American College of Rheumatology [35], were isolated as described previously [36]. FLS from rats with CIA, induced with disease as described below, were isolated 14 days after the rats developed signs of disease, as described previously [37] by isolating the synovial paw joints, incubating them with Gibco type IV collagenase (Life Technologies, Carlsbad, CA, USA) for $1 \mathrm{~h}$ at $37^{\circ} \mathrm{C}$, and culturing adherent cells in DMEM supplemented with $2 \mathrm{mg} / \mathrm{ml} \mathrm{L}$-glutamine, $0.1 \mu \mathrm{g} / \mathrm{ml}$ streptomycin, 10 $\mathrm{U} / \mathrm{ml}$ penicillin, and $10 \%$ FBS. CIA-FLS and RA-FLS were considered pure after the third passage of the adherent cells and were used between passages 3 and 10 .

\section{KCa1.1 and Kv1.3 channel blockers}

The KCa1.1 blocker paxilline was purchased from Fermentek (Jerusalem, Israel), and the Kv1.3 blocker ShK-186/Dalazatide, synthesized under good manufacturing practice conditions by CSBio (Menlo Park, CA, USA), was a kind gift from Kineta, Inc. (Seattle, WA, USA). The KCa1.1 blocker IbTX was synthesized as described previously [21]. Each batch of blockers was tested for channel block by patch-clamping on HEK 293 cells stably expressing KCa1.1 and on L929 cells stably expressing Kv1.3 [38] using a Port-a-Patch automated patch-clamp system (Nanion, Munich, Germany) as described elsewhere [11, 21]. For all in vitro and in vivo studies, potassium channel blockers were used at concentrations known to significantly inhibit the pathogenic phenotypes of FLS and $\mathrm{T}_{\mathrm{EM}}$ cells and were chosen on the basis of pharmacokinetic and dose-dependence studies $[6,17,19]$.

\section{Measuring MHC class II molecule, B7-H3, ICAM-1, and CD40 expression levels in CIA-FLS}

CIA-FLS were treated with $100 \mathrm{ng} / \mathrm{ml}$ recombinant IFN- $\gamma$ (MilliporeSigma, Burlington, MA, USA) for $72 \mathrm{~h}$ in the presence or absence of $20 \mu \mathrm{M}$ paxilline. To measure levels of MHC class II molecules, cells were scraped from culture dishes and left either intact or permeabilized with $0.5 \%$ saponin, followed by staining with an anti-MHC class II molecule antibody (clone HIS19; LSBio, Seattle, WA, USA), recognizing the RT1L haplotype expressed by Lewis rats [39], followed by a secondary antibody labeled with the Alexa Fluor 488 fluorophore (Life Technologies). For measurement of B7-H3, ICAM-1, and CD40 expression levels, cells were scraped from their culture flasks and stained with antibodies against B7-H3 (clone MIH42; BioLegend, San
Diego, CA, USA) or CD40 (clone 5c3; BioLegend), followed by Alexa Fluor 488-conjugated secondary antibodies, or ICAM-1 (clone HA58; BD Biosciences, San Jose, CA, USA) conjugated to allophycocyanin (APC). Fluorescence was measured using a FACSCanto II flow cytometer (BD Biosciences) and analyzed using FlowJo software (FlowJo, Ashland, OR, USA).

\section{Preparation of $\mathrm{T}_{\mathrm{EM}}$ cell conditioned medium}

Primary Lewis rat ovalbumin-specific $\mathrm{CD}^{+} \mathrm{Th} 1 \mathrm{~T}_{\mathrm{EM}}$ cells were provided by Alexander Flügel (University Medical Center, Göttingen, Germany) and maintained in culture as described previously [40]. $\mathrm{T}_{\mathrm{EM}}$ cell conditioned medium was prepared by stimulating $3 \times 10^{6} \mathrm{~T}_{\mathrm{EM}}$ cells with $150 \times 10^{6}$ irradiated (30 Gy) Lewis rat thymus-derived antigen-presenting cells, which were obtained by making single-cell suspensions of freshly harvested thymuses of healthy Lewis rats [41] that were loaded with $10 \mu \mathrm{g} / \mathrm{ml}$ ovalbumin (MilliporeSigma) in the presence or absence of $100 \mathrm{nM}$ ShK-186. Supernatants were collected after $48 \mathrm{~h}$ of stimulation and stored at $-80^{\circ} \mathrm{C}$ for later use.

\section{Measuring ex vivo antigen presentation}

CIA-FLS antigen presentation was measured as described elsewhere [26]. CIA-FLS (10,000 cells/well) were plated in 24-well plates and treated for $48 \mathrm{~h}$ with $100 \mathrm{ng} /$ $\mathrm{ml}$ recombinant IFN- $\gamma$ with or without $20 \mu \mathrm{M}$ paxilline. Medium was then changed to one containing IFN- $\gamma$, paxilline, and either $10 \mu \mathrm{g} / \mathrm{ml}$ ovalbumin or myelin basic protein as relevant or irrelevant antigens, respectively, and cells were cultured for an additional $72 \mathrm{~h}$. CIA-FLS were then washed; 10,000 ovalbumin-specific $\mathrm{T}_{\mathrm{EM}}$ cells were added to each well; and cocultures were grown for $72 \mathrm{~h}$ in medium containing $10 \mu \mathrm{g} / \mathrm{ml}$ ovalbumin or myelin basic protein, but without IFN- $\gamma$ or paxilline. Proliferation of the $\mathrm{T}_{\mathrm{EM}}$ cells was measured by $\left[{ }^{3} \mathrm{H}\right]$ thymidine incorporation as described elsewhere [10, 11, 42].

\section{Imaging conjugates between CIA-FLS and $\mathrm{T}_{\mathrm{EM}}$ cells}

CIA-FLS were stimulated for $72 \mathrm{~h}$ with $100 \mathrm{ng} / \mathrm{ml} \mathrm{IFN- \gamma}$ and loaded with $10 \mu \mathrm{g} / \mathrm{ml}$ ovalbumin for $2-3 \mathrm{~h}$ in the presence of IFN- $\gamma$. The CIA-FLS were then labeled with CellTrace Violet dye (Thermo Fisher Scientific, Waltham, MA, USA), and ovalbumin-specific $\mathrm{T}_{\mathrm{EM}}$ cells were labeled with carboxyfluorescein succinimidyl ester (CFSE) (Thermo Fisher Scientific). The CIA-FLS were then removed from their culture flasks and placed in 1.5-ml Eppendorf tubes with the ovalbumin-specific $\mathrm{T}_{\mathrm{EM}}$ cells at a 4:1 ratio of $\mathrm{T}_{\mathrm{EM}}$ cells to CIA-FLS. The cocultures were briefly centrifuged, incubated at $37^{\circ} \mathrm{C}$ for 30 min in the presence or absence of either $20 \mu \mathrm{M}$ paxilline or $100 \mathrm{nM}$ ShK-186, and fixed with $4 \%$ paraformaldehyde. Cells were then stained with an anti-CD3 antibody 
conjugated to APC (antibody clone 1F4; BD Biosciences) and analyzed with an Amnis Imaging Flow Cytometer (MilliporeSigma) to image cell conjugates and the formation of an immune synapse or with a FACSCanto II flow cytometer to quantify cell conjugates, with gating completed to exclude single cells.

\section{Measuring ex vivo $\mathrm{T}$ cell migration}

CIA-FLS (5000 cells/well) were plated in 24-well plates and stimulated for $24 \mathrm{~h}$ with $100 \mathrm{ng} / \mathrm{ml} \mathrm{IFN- \gamma}$ with or without $20 \mu \mathrm{M}$ paxilline. Medium was then changed, and Transwell inserts with $5-\mu \mathrm{m}$ pores (Corning, Corning, NY, USA) were placed on top of the CIA-FLS-containing wells. Fifty thousand Lewis rat $\mathrm{T}_{\mathrm{EM}}$ cells were placed in the Transwell, and $\mathrm{T}$ cells were allowed to migrate toward the FLS. After $6 \mathrm{~h}$, the number of $\mathrm{T}$ cells that migrated through the Transwell and into the well containing the CIA-FLS was counted with a hemocytometer, as described previously [43].

\section{Measuring ex vivo FLS invasion toward T cell supernatants}

CIA-FLS invasion assays were completed as previously described [17, 19, 36, 37]. Briefly, CIA-FLS were placed in the top well of a Matrigel-coated Transwell insert (Corning) in serum-free culture medium. Culture medium containing $20 \% \mathrm{~T}$ cell conditioned medium or $10 \%$ FBS was placed in the well beneath the Transwell, and CIA-FLS were allowed to migrate for $24 \mathrm{~h}$. The Matrigel and noninvading cells were then removed, and cells that invaded through the Transwell were counted.

\section{Measuring the effect of $\mathrm{T}$ cells or recombinant cytokines on FLS MHC class II and KCa1.1 expression}

CIA-FLS (10,000 cells/well) were plated in 96-well plates and incubated for $72 \mathrm{~h}$ in $\mathrm{T}_{\mathrm{EM}}$ cell-conditioned medium supplemented with $10 \%$ FBS. For RA-FLS, cells were stimulated for $24 \mathrm{~h}$ in the presence or absence of $100 \mathrm{ng} / \mathrm{ml} \mathrm{re-}$ combinant TNF- $\alpha$ (Bachem, Bubendorf, Switzerland), IL-1 $\beta$ (R\&D Systems, Minneapolis, MN, USA), receptor activator of nuclear factor $\kappa B$ ligand (RANKL) (MilliporeSigma), or IFN- $\gamma$ (MilliporeSigma). The FLS were then analyzed by flow cytometry for the plasma membrane expression of MHC class II molecules, as described above. For detection of KCa1.1 levels, cells were permeabilized with $0.5 \%$ saponin and stained with an anti-KCa1.1 $\alpha$ subunit antibody (clone L6/60; NeuroMab/UC Davis, Davis, CA, USA) followed by an Alexa Fluor 488-conjugated secondary antibody, with analysis by flow cytometry.

\section{Inducing, monitoring, and treating rat models of RA}

CIA was induced in Lewis rats by a subcutaneous injection at the base of the tail with $200 \mu \mathrm{l}$ of a 1:1 emulsion of $2 \mathrm{mg} / \mathrm{ml}$ porcine type II collagen (Chondrex, Redmond,
WA, USA) with incomplete Freund's adjuvant. Seven days after the first injection, rats were given a booster of $100 \mu \mathrm{l}$ of the collagen and adjuvant emulsion [21, 44]. PIA was induced in Dark Agouti rats by a subcutaneous injection of $150 \mu \mathrm{l}$ of pristane (MP Biomedicals, Santa Ana, CA, USA) at the base of the tail $[6,17,21]$. Disease onset was defined as development of at least one swollen or red paw joint. Clinical scores were determined daily as described previously $[6,9,17]$ by assigning 1 point for each swollen or red toe joint and 5 points for each swollen wrist or ankle, giving each rat a maximum possible score of 60 . Upon disease onset, rats were treated every other day with vehicle (P6N buffer; $10 \mathrm{mM}$ sodium phosphate, $0.8 \%$ $\mathrm{NaCl}, 0.05 \%$ polysorbate $20, \mathrm{pH} 6.0$ ) [9], $20 \mathrm{mg} / \mathrm{kg}$ paxilline through intraperitoneal injection, $0.5 \mathrm{mg} / \mathrm{kg} \mathrm{IbTX}$ subcutaneously, $0.1 \mathrm{mg} / \mathrm{kg}$ ShK-186 subcutaneously, or a combination of $0.1 \mathrm{mg} / \mathrm{kg}$ ShK-186 and either $20 \mathrm{mg} / \mathrm{kg}$ paxilline or $0.5 \mathrm{mg} / \mathrm{kg}$ IbTX, doses known to reduce disease severity in rat models of RA and chosen on the basis of pharmacokinetic studies and dose-dependence studies $[6,17,21]$. Randomization of rats to treatment groups was completed in which every fourth rat that developed signs of disease on a given day was placed in the same treatment group, thereby disregarding differences in basal disease severity on the day each rat developed signs of disease and accounting for differences in the time between immunization and when a rat developed signs of disease.

\section{Measuring KCa1.1 expression by FLS from rats with CIA}

FLS were isolated from rats with CIA in each treatment group 14 days after disease onset. They were permeabilized with $0.5 \%$ saponin and stained with an anti-KCa1.1 $\alpha$ antibody (NeuroMab), followed by an Alexa Fluor 488-conjugated secondary antibody, and cells were analyzed by flow cytometry as described above. Linear regression analysis between $\mathrm{KCa} 1.1 \alpha$ staining intensity of FLS from individual rats and each rat's clinical score on the day of cell collection was completed with Prism software (GraphPad Software, La Jolla, CA, USA).

\section{T cell phenotyping of lymph node cells of rats with CIA}

The draining inguinal lymph nodes were collected from rats with CIA in each treatment group 14 days after disease onset. Single-cell suspensions were made of each lymph node and stained for expression of CD3 conjugated to APC (clone 1F4; BD Biosciences), CD4 conjugated to phycoerythrin (PE)-cyanine 7 (clone W3/25; BioLegend), CD8 conjugated to PE (clone OX-8; BD Biosciences), CD25 conjugated to fluorescein isothiocyanate (clone OX-39; BD Biosciences), and CD45RC conjugated to biotin (clone OX-22; Thermo Fisher Scientific) and further stained with streptavidin conjugated to Alexa Fluor 405 . Cells were analyzed by flow cytometry as described above. 


\section{X-rays and histology}

Rats with either PIA or CIA were killed after either 21 or 14 days of treatment, and their paws were collected for histology and $\mathrm{X}$-ray analysis. X-rays were completed using an In-Vivo Xtreme Imaging System (Bruker BioSpin, Billerica, MA, USA) on the hind paws and were used by an investigator blinded to treatment groups to assess the presence or absence of abnormal bone structures and erosions. Following collection, hind paws were fixed, decalcified, embedded in paraffin, sectioned, and stained with either H\&E or Safranin O/Fast Green. Images of synovial paw joints were taken with an Olympus BX41 microscope equipped with an Olympus Q Color 5 camera at $10 \times$ magnification (Olympus, Center Valley, PA, USA). Scoring of disease parameters from histology was completed by an investigator blinded to treatment groups, as described elsewhere [45], in which immune infiltrates, pannus extensions, hyperplasia, and cartilage erosions were quantified by giving a score of 0 when absent, a score of 1 when mild, a score of 2 when moderate, and a score of 3 when a severe amount of these parameters was present.

\section{Serum chemistry and cytokine analyses}

At the end of the CIA trial, blood was collected by terminal cardiac puncture from each rat, and serum was stored at $-80^{\circ} \mathrm{C}$. Blood chemistry panels were completed on five randomly selected rats per group through the Center for Comparative Medicine at Baylor College of Medicine by investigators blinded to each rat's treatment. Serum cytokine analyses were completed on five or six randomly selected rats per group by using a rat cytokine array (Eve Technologies, Calgary, AB, Canada) in a blinded manner.

\section{Statistical analysis}

All statistical analyses were completed by using the Mann-Whitney $U$ test or Wilcoxon matched-pairs signed-rank test, except for the CIA and PIA clinical scores analyses, which were completed using repeated measures one-way analysis of variance with Bonferroni post hoc test. All data are shown as mean $\pm \mathrm{SEM}$, and $p$ values less than 0.05 were considered significant. All statistical analyses were completed using Prism software.

\section{Results}

\section{$\mathrm{KCa} 1.1$ regulates the ability of CIA-FLS to activate and} attract $\mathrm{T}_{\mathrm{EM}}$ cells

Upon cytokine stimulation, FLS secrete chemokines that attract $\mathrm{T}$ cells, including CXCL10, IL-6, and fractalkine [46-49]. We sought to determine if KCa1.1 regulates the ability of FLS to stimulate T cell migration. To do this, we treated FLS isolated from Lewis rats with CIA with paxilline and IFN- $\gamma$ and then used Transwells to monitor syngeneic $C D 4^{+} \mathrm{T}_{\mathrm{EM}}$ cell migration toward the CIA-FLS. $\mathrm{T}_{\mathrm{EM}}$ cells migrated in equivalent amounts toward unstimulated CIA-FLS and CIA-FLS that had been treated for $72 \mathrm{~h}$ with paxilline. However, significantly more $T_{\mathrm{EM}}$ cells migrated toward the CIA-FLS that had been pretreated with IFN- $\gamma$ for $72 \mathrm{~h}$. This effect was eliminated when the CIA-FLS were treated with both IFN- $\gamma$ and paxilline, indicating that KCa1.1 block influences the ability of IFN- $\gamma$-activated CIA-FLS to induce $\mathrm{T}_{\mathrm{EM}}$ cell migration (Fig. 1a).

Besides attracting $\mathrm{T}$ cells toward them, FLS can stimulate the proliferation of $\mathrm{CD}^{+} \mathrm{T}$ cells by acting as antigen-presenting cells [26]. To confirm the antigen-presenting capability of FLS, we first verified that CIA-FLS physically bind to and form cell-cell conjugates with $\mathrm{CD}^{+} \mathrm{T}_{\mathrm{EM}}$ cells. CIA-FLS were stimulated with IFN- $\gamma$ for $72 \mathrm{~h}$, loaded with ovalbumin, and labeled with the CellTrace Violet fluorescent dye. They were allowed to interact with ovalbumin-specific Lewis rat $\mathrm{CD}^{+} \mathrm{T}_{\mathrm{EM}}$ cells labeled with the CFSE fluorescent dye. We observed physical interactions between CIA-FLS and $\mathrm{T}_{\mathrm{EM}}$ cells, with CD3 accumulation observed at the contact site between the CIA-FLS and $\mathrm{T}_{\mathrm{EM}}$ cells (Fig. 1b), suggesting formation of an immune synapse between the two cell types [50, 51]. To determine if either KCa1.1 or Kv1.3 block prevents the formation of cell conjugates, either paxilline or ShK-186 was added to the mixtures of IFN- $\gamma$-treated CIA-FLS and $\mathrm{T}_{\mathrm{EM}}$ cells while the cells were allowed to interact. Neither paxilline nor ShK-186, alone or in combination, acutely altered the proportion of cell conjugates (Fig. 1c and d).

To confirm that FLS can stimulate the proliferation of $\mathrm{CD}^{+}{ }^{+} \mathrm{T}$ cells and determine if KCa1.1 block reduces the FLS ability to stimulate $\mathrm{T}$ cell proliferation, CIA-FLS were stimulated with IFN- $\gamma$ in the presence or absence of paxilline, loaded with ovalbumin, and cocultured with syngeneic ovalbumin-specific $\mathrm{CD}_{4}^{+} \mathrm{T}_{\mathrm{EM}}$ cells. The cocultures of ovalbumin-specific $\mathrm{T}_{\mathrm{EM}}$ cells with CIA-FLS stimulated with IFN- $\gamma$ and loaded with ovalbumin exhibited significantly greater proliferation than the cocultures containing $\mathrm{T}$ cells with CIA-FLS stimulated with IFN- $\gamma$ in the presence of paxilline and loaded with ovalbumin. Loading IFN- $\gamma$-stimulated CIA-FLS with an irrelevant antigen (myelin basic protein) failed to induce the proliferation of the ovalbumin-specific $\mathrm{T}_{\mathrm{EM}}$ cells (Fig. 1e).

\section{KCa1.1 regulates surface expression of MHC class II by FLS}

IFN- $\gamma$ stimulates MHC class II molecule expression by RA-FLS [22, 23, 26]. In order to determine if KCa1.1 regulates this upregulation, CIA-FLS were treated with IFN- $\gamma$ in the presence or absence of the KCa1.1 blocker paxilline. IFN- $\gamma$-treated CIA-FLS had an increase in the total and plasma membrane expression of MHC class II 


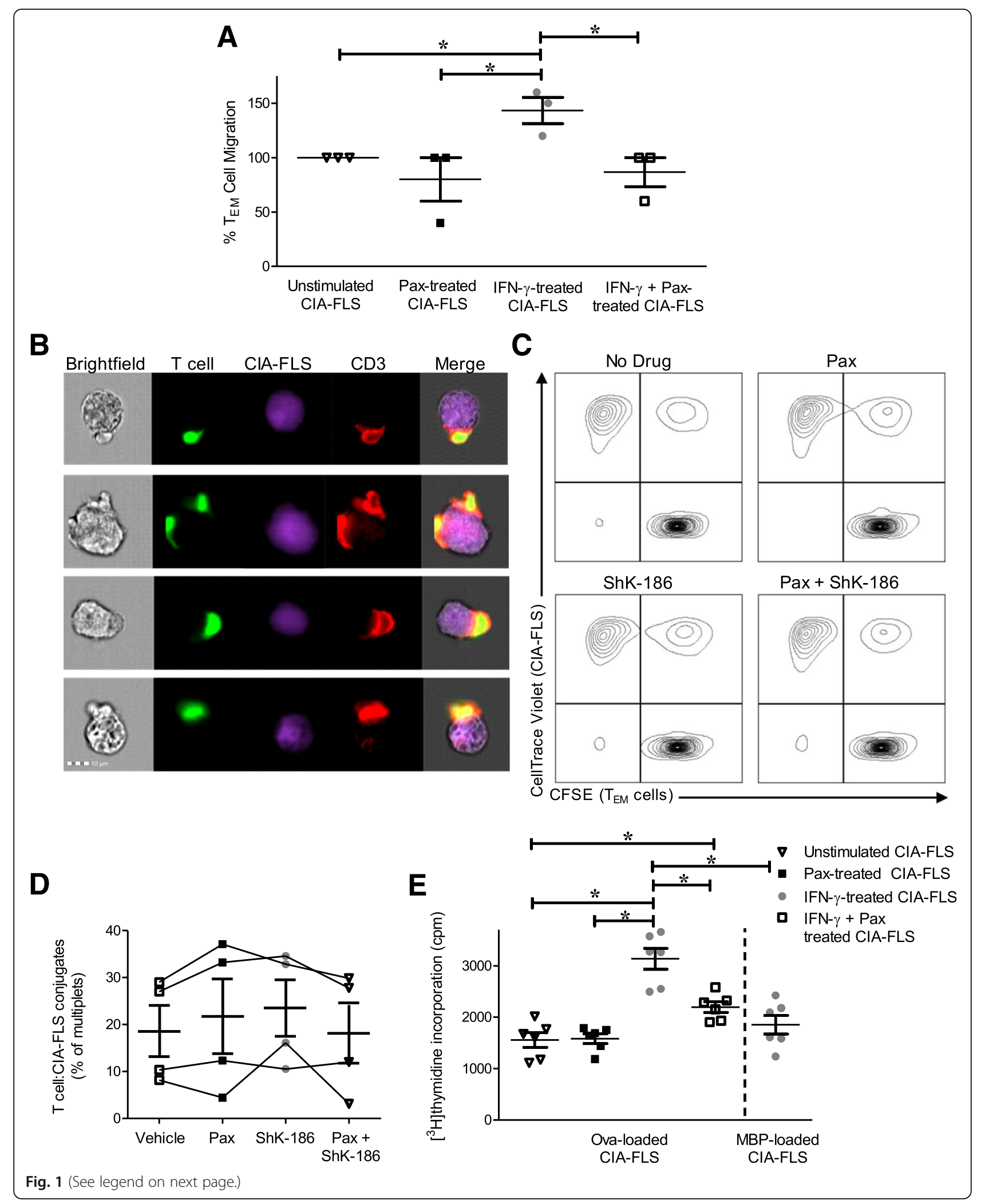


(See figure on previous page.)

Fig. 1 Collagen-induced arthritis fibroblast-like synoviocytes (CIA-FLS) modulate T cell migration and serve as antigen-presenting cells in a KCa1.1dependent manner. a Effector memory $T\left(T_{E M}\right)$ cell migration toward CIA-FLS that were cultured for $72 \mathrm{~h}$ in the presence or absence of interferon (IFN)- $\gamma$, paxilline, or both. Data are presented as mean \pm SEM $(n=3)$. b Flow cytometric images of ovalbumin-loaded, IFN- $\gamma$-stimulated CIA-FLS (violet) and ovalbumin-specific TEM cell (green) cocultures that were stained for CD3 (red) after cells were allowed to interact for 30 min. c Flow cytometric plots of mixtures of ovalbumin-loaded, IFN-y-stimulated CIA-FLS (CellTrace Violet) and ovalbumin-specific $\mathrm{T}_{\text {EM }}$ cells (carboxyfluorescein succinimidyl ester [CFSE]) that were allowed to interact for $30 \mathrm{~min}$ in the presence or absence of paxilline (Pax) or ShK-186. Flow cytometric gating was completed to exclude single cells. $\mathbf{d}$ Quantifications of the proportion of CIA-FLS and TEM cells that form conjugates, as defined by the proportion of CellTrace Violet ${ }^{+} \mathrm{CFSE}^{+}$multiplets or nonsingle cells detected by flow cytometry, from experiments in (c). Data are presented as mean $\pm \operatorname{SEM}$ ( $n=4$ separate experiments). e Proliferation of cocultures of CIA-FLS with ovalbumin-specific CD4 ${ }^{+} T_{\text {EM }}$ cells in which CIA-FLS were pretreated with IFN- $\gamma$, paxilline (Pax), or both and loaded with either ovalbumin (OVA) or myelin basic protein (MBP). Data are presented as mean $\pm \operatorname{SEM}(n=6) .{ }^{*} p<0.05$

molecules. Examination of intact CIA-FLS indicates that although IFN- $\gamma$ induces an increase in MHC class II molecules over $72 \mathrm{~h}$, as others have described with RA-FLS [22, 23, 26], cotreatment with paxilline prevents this increase (Fig. 2a and b). However, staining for $\mathrm{MHC}$ class II in permeabilized CIA-FLS indicates that paxilline treatment does not reduce the total amount of $\mathrm{MHC}$ class II protein expressed, as compared with IFN- $\gamma$-treated cells (Fig. $2 \mathrm{c}$ and $\mathrm{d}$ ). Together, these data demonstrate that $\mathrm{KCa} 1.1$ block with paxilline reduces the plasma membrane localization of MHC class II molecules in CIA-FLS, but it does not influence the total amount of MHC class II protein synthesized following IFN- $\gamma$ treatment.

RA-FLS also express the costimulatory molecules B7-H3, ICAM-1, and CD40 [24, 25, 27]. We examined their expression by CIA-FLS following stimulation with IFN- $\gamma$ in the presence or absence of paxilline. All of these proteins were present in CIA-FLS, and neither IFN- $\gamma$ nor paxilline had an effect on the proportion of cells expressing them (Fig. 2e). This result was confirmed in RA-FLS (data not shown). We also observed no differences in the expression levels of these proteins between treatment groups, as determined by mean fluorescence intensity, in both RA-FLS and CIA-FLS (data not shown).

\section{$\mathrm{T}_{\mathrm{EM}}$ cells and $\mathrm{Kv} 1.3$ regulate ex vivo phenotype of $\mathrm{CIA}$ - FLS}

A variety of cytokines, including IFN- $\gamma$, IL-17, and TNF- $\alpha$, are known to influence the activation of FLS [28-30]. It is therefore likely that $\mathrm{T}_{\mathrm{EM}}$ cells and the cytokines they secrete following activation can directly influence the aggressive phenotype of FLS. ShK-186 treatment prevents $\mathrm{T}_{\mathrm{EM}}$ cell activation and $\mathrm{T}_{\mathrm{EM}}$ cells' ability to secrete a number of cytokines, including IL-2, IL-4, and IFN- $\gamma[6,52]$. We therefore sought to determine if cytokines secreted by $\mathrm{T}_{\mathrm{EM}}$ cells can influence the activation of FLS and if Kv1.3 blockade on $\mathrm{T}_{\mathrm{EM}}$ cells influences FLS activation. CIA-FLS cultured in conditioned medium from antigen-stimulated syngeneic $\mathrm{CD}^{+}{ }^{+} \mathrm{T}_{\mathrm{EM}}$ cells expressed significantly higher levels of $\mathrm{KCa} 1.1 \alpha$ (Fig. 3a) and MHC class II molecules (Fig. 3b) at their plasma membrane than CIA-FLS grown in conditioned medium from unstimulated $\mathrm{T}_{\mathrm{EM}}$ cells. However, CIA-FLS cultured in the conditioned medium from $\mathrm{T}_{\mathrm{EM}}$ cells that were stimulated in the presence of ShK-186 had significantly reduced MHC class II and $\mathrm{KCa} 1.1 \alpha$ expression compared with those grown in conditioned medium of $\mathrm{T}_{\mathrm{EM}}$ cells stimulated in the absence of ShK-186 (Fig. 3a and b). These results suggest that the cytokines secreted by activated $\mathrm{T}_{\mathrm{EM}}$ cells can influence FLS expression of MHC class II and $\mathrm{KCa} 1.1$ and that Kv1.3 blockade reduces the $\mathrm{T}_{\mathrm{EM}}$ cells' ability to do so. To determine whether cytokines alter KCa1.1 expression in human FLS, we stimulated RA-FLS with either recombinant TNF- $\alpha$, IL-1 $\beta$, RANKL, or IFN- $\gamma$ and assessed them for the expression of $\mathrm{KCa} 1.1 \alpha$. Compared with unstimulated RA-FLS, those treated with either of these cytokines exhibited increased $\mathrm{KCa} 1.1 \alpha$ expression (Fig. 3c).

Invasiveness is a hallmark of aggressive FLS during RA and its animal models and is enhanced by proinflammatory cytokines such as IFN- $\gamma$, IL-17, and TNF- $\alpha$ [28-30]. We therefore examined the influence of the $\mathrm{T}_{\mathrm{EM}}$ cell conditioned medium on CIA-FLS invasion through Matrigel-coated Transwell inserts. CIA-FLS exposed to conditioned medium from antigen-stimulated $\mathrm{T}_{\mathrm{EM}}$ cells were significantly more invasive than those exposed to medium from unstimulated $\mathrm{T}_{\mathrm{EM}}$ cells, indicating that activated $\mathrm{T}_{\mathrm{EM}}$ cells can enhance CIA-FLS invasion. However, CIA-FLS exposed to conditioned medium of $\mathrm{T}_{\mathrm{EM}}$ cells stimulated in the presence of ShK-186 were significantly less invasive (Fig. 3d), indicating that Kv1.3 activity regulates the $\mathrm{T}_{\mathrm{EM}}$ cell ability to induce FLS invasiveness.

\section{A combined therapy of Kv1.3 and KCa1.1 blockers is more effective than monotherapies in reducing disease severity in CIA}

We previously found that monotherapies with either Kv1.3 or KCa1.1 blockers reduce disease severity in rat models of RA, but that each monotherapy does not completely stop disease $[6,7,11,17,21]$. This is presumably due to each monotherapy only directly inhibiting either $\mathrm{T}_{\mathrm{EM}}$ cells or FLS while leaving other pathogenic cell types intact. We therefore sought to determine if a 


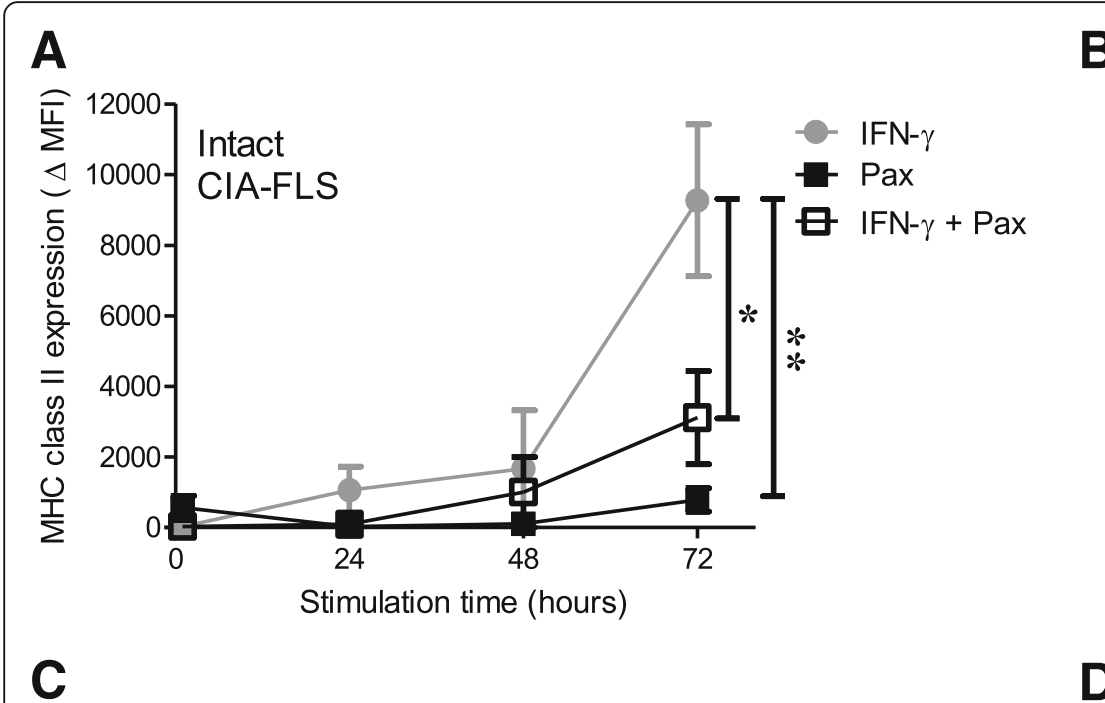

\section{B}
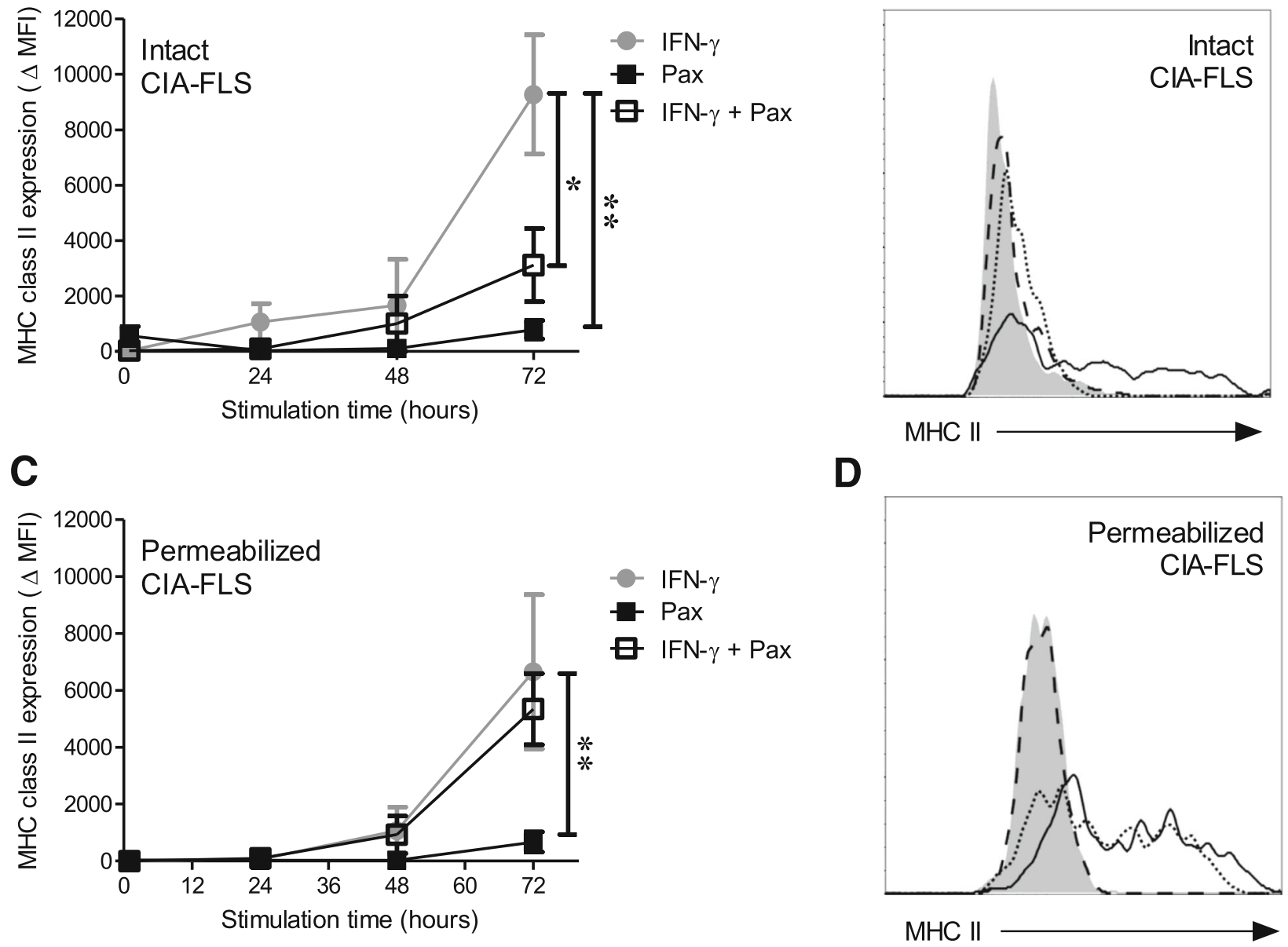

E

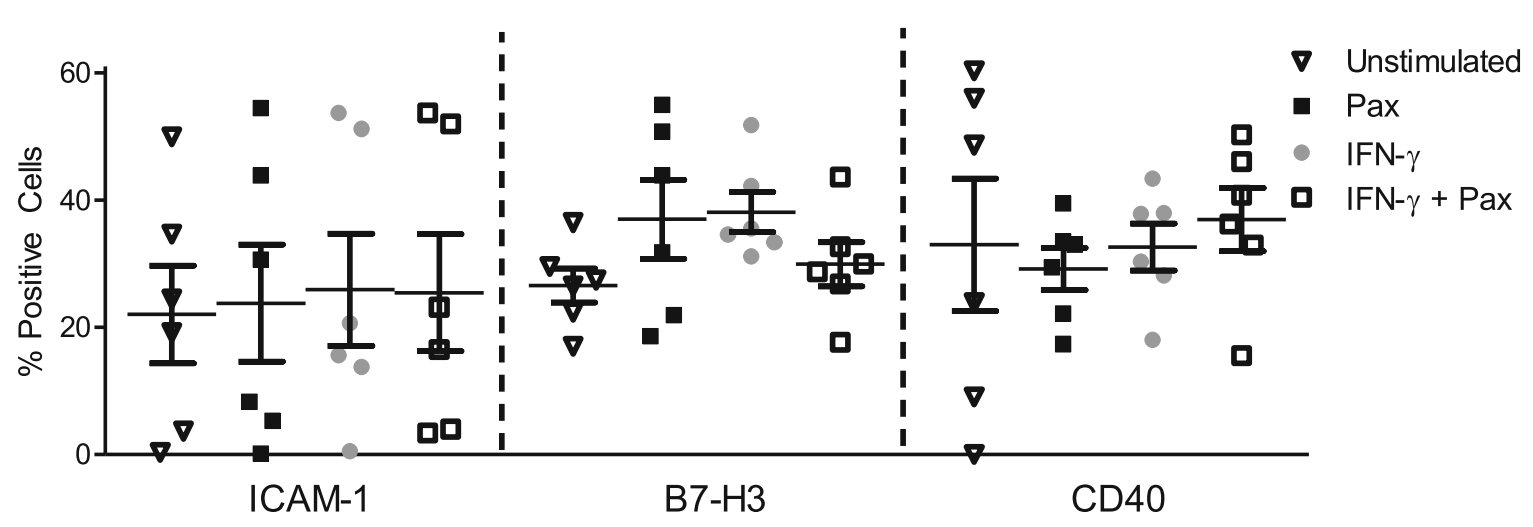

Fig. 2 (See legend on next page.) 
(See figure on previous page.)

Fig. 2 Collagen-induced arthritis fibroblast-like synoviocytes (CIA-FLS) express major histocompatibility complex (MHC) class II molecules that are regulated through KCa1.1, as well as antigen-presenting proteins. a CIA-FLS plasma membrane expression of MHC class II protein following stimulation for $72 \mathrm{~h}$ with IFN- $\gamma$ (gray circles), paxilline (Pax; black squares), or interferon (IFN)- $\gamma$ and paxilline (open squares). Data are presented as mean \pm SEM $(n=3-8$ CIA-FLS donors). $\mathbf{b}$ Flow cytometric histogram of CIA-FLS stained for the plasma membrane expression of MHC class II protein in cells treated with paxilline for $72 \mathrm{~h}$ (dashed line), stimulated for $72 \mathrm{~h}$ with IFN- $\gamma$ (solid line), or stimulated for $72 \mathrm{~h}$ with IFN- $\gamma$ and paxilline (dotted line). The shaded histogram represents background staining. c MHC class II molecule expression of CIA-FLS that were permeabilized with saponin prior to staining for MHC class II in cells treated for $72 \mathrm{~h}$ with IFN- - (gray circles), paxilline (black squares), or IFN- $\gamma$ and paxilline (open squares). Data are presented as mean \pm SEM ( $n=3-6$ CIA-FLS donors). d Flow cytometric histogram of CIA-FLS stained for MHC class II molecules following permeabilization with saponin in cells treated for $72 \mathrm{~h}$ with IFN- $\gamma$ (solid line), paxilline (dashed line), or IFN- $y$ and paxilline (dotted line). The shaded histogram represents background staining. e Expression of intercellular adhesion molecule (ICAM)-1, B7-H3, and CD40 by CIA-FLS following treatment for $72 \mathrm{~h}$ with IFN- $\gamma$, paxilline, or IFN- $\gamma$ and paxilline. Data are presented as mean \pm SEM ( $n=6$ CIA-FLS donors). ${ }^{*} p<0.05,{ }^{* *} p<0.01$

combined therapy of Kv1.3 and KCa1.1 blockers could work in synergy to further ameliorate disease severity in animal models of RA.

Upon disease onset, rats with CIA were treated with vehicle, the Kv1.3 blocker ShK-186, the KCa1.1 blocker IbTX, or both ShK-186 and IbTX every other day.
Vehicle-treated rats developed clinical scores of $29 \pm 3$ (mean $\pm \mathrm{SEM}$ ), whereas rats treated with either of the monotherapies of ShK-186 and IbTX developed scores of $18 \pm 2$ and $20 \pm 2$, respectively, indicating an approximately $30-40 \%$ decrease in disease severity in the monotherapy-treated animals. In contrast, rats treated
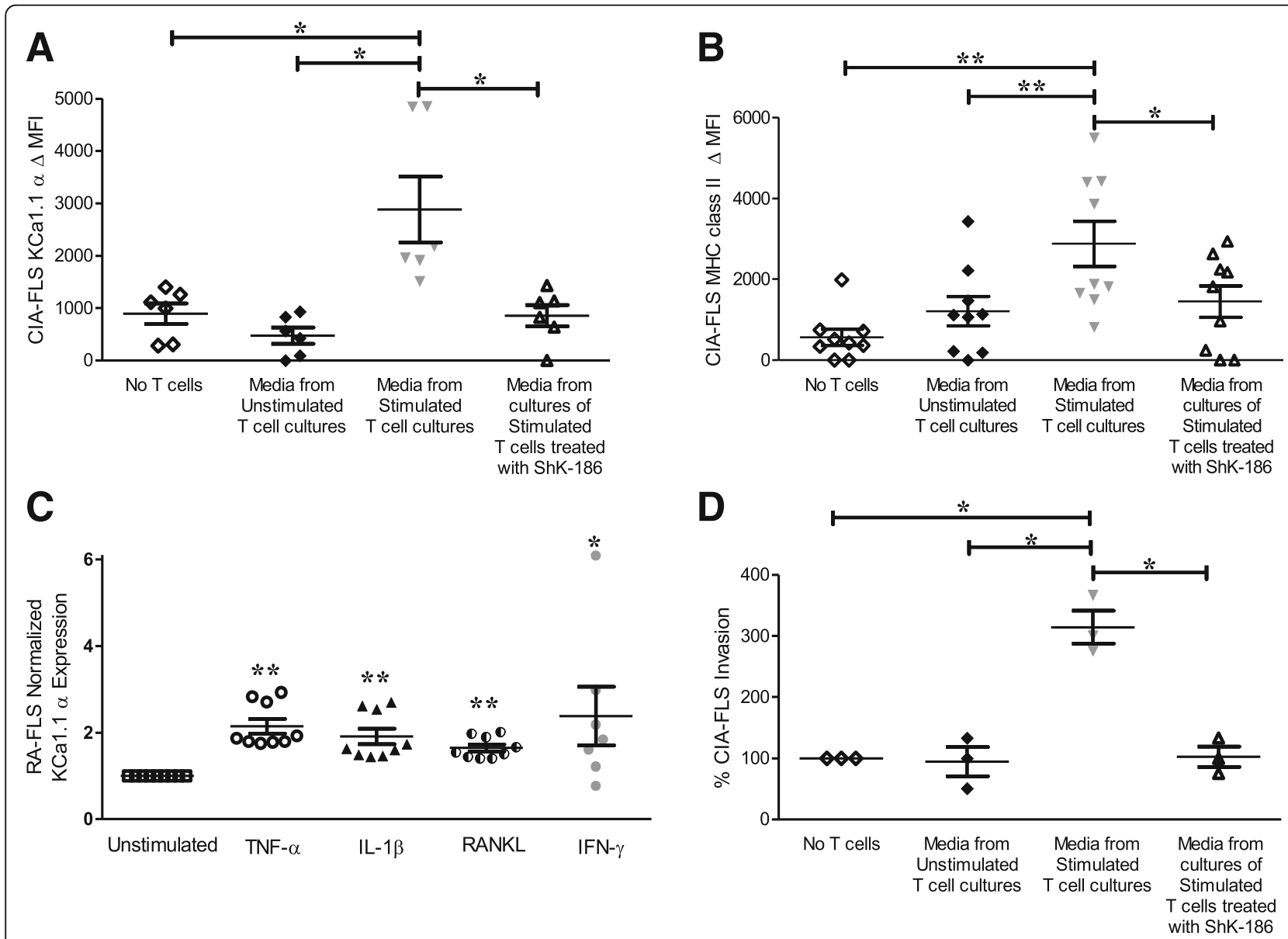

Fig. 3 Effector memory T (TEM) cells and cytokines regulate the phenotype of fibroblast-like synoviocytes (FLS). KCa1.1a (a) and major histocompatibility complex (MHC) class II molecule (b) plasma membrane expression levels by collagen-induced arthritis (CIA)-FLS cultured for $72 \mathrm{~h}$ in the conditioned medium of $T_{E M}$ cells that were antigen-stimulated in the presence or absence of ShK-186. Data are presented as mean \pm SEM ( $n=6-9$ CIA-FLS donors). c KCa1.1a protein expression by rheumatoid arthritis (RA)-FLS, as determined by flow cytometry, following $24 \mathrm{~h}$ of stimulation with recombinant cytokines. Data are presented as mean \pm SEM ( $n=7-9$ RA-FLS donors). $\mathbf{d}$ CIA-FLS invasion through Matrigel-coated Transwells toward the conditioned medium of $T_{E M}$ cells that were antigen-stimulated in the presence or absence of ShK-186. Data are presented as mean \pm SEM ( $n=3$ CIA-FLS donors). ${ }^{*} p<0.05,{ }^{* *} p<0.01$ 
with a combined therapy of ShK-186 and IbTX exhibited significantly less inflammation, with clinical scores of only $10 \pm 2$, or an approximately $65 \%$ reduction in disease severity. Furthermore, whereas vehicle-treated and monotherapy-treated rats exhibited an increase in the clinical scores over time, rats treated with the combined therapy displayed stable, low clinical scores over the course of our studies (Fig. 4a).

X-rays of the hind paws of rats from each treatment group indicated that vehicle-treated rats developed significant bone erosions around the synovial joints, which were reduced by both the monotherapies and the combined therapy (Fig. 4b). Safranin O/Fast Green staining of tissue sections from paw joints in each treatment group demonstrated fewer cartilage erosions in the synovial joints of monotherapy-treated rats and in the combined therapy animals. H\&E staining showed that immune infiltrates were reduced in both the monotherapy-treated and combined therapy-treated rats (Fig. 4b and c). We also collected serum from CIA rats in each treatment group 14 days after disease onset and from healthy rats for serum chemistry analyses, which are summarized in Additional file 1: Table S1.

Analyses of cytokine levels in the serum of CIA rats from each treatment group that were collected at the end of the in vivo studies and of healthy rats were also completed. IL-4, IL-12, IL-17A, MCP-1, and TNF- $\alpha$ were increased in vehicle-treated CIA rats compared with in healthy rats, whereas there were no significant differences in the levels of these cytokines in CIA rats treated with ShK-186 or IbTX, alone or in combination, when compared with healthy rats (Fig. 5a-e). IL-2 was increased in CIA rats treated with vehicle, ShK-186, or IbTX, though there was no significant differences in IL-2 levels between healthy rats and rats with CIA treated with both ShK-186 and IbTX (Fig. 5f). IFN- $\gamma$ was reduced in CIA rats treated with either potassium channel blockers, alone or in combination. IL-5 was increased in CIA rats treated with vehicle or either monotherapy of ShK-186 or IbTX. Vascular endothelial growth factor (VEGF) was decreased in CIA rats treated with both ShK-186 and IbTX, but it was not significantly different in healthy rats compared with CIA rats treated with vehicle or a potassium channel blocker monotherapy. Macrophage inflammatory protein (MIP)- $1 \alpha$ was decreased in rats with CIA treated with ShK-186 or both IbTX and ShK-186 compared with healthy rats. Fractalkine, granulocyte-macrophage colony-stimulating factor, GRO/keratinocyte chemoattractant, leptin, LIX, MIP-2, and RANTES (regulated upon activation normal $\mathrm{T}$ cell expressed and secreted) were decreased in all rats with CIA compared with in healthy rats, regardless of treatment group. We found no differences in the amount of serum epidermal growth factor, granulocyte colony-stimulating factor, eotaxin, IL-1 $\alpha$, IL-1 $\beta$, IL-6, IL-10, IL-13, IL-18, or IP-10 between healthy rats and rats with CIA (Fig. $5 \mathrm{~g}-\mathrm{i}$ ). These data are summarized in Fig. 5 and Additional file 2: Table S2.

\section{FLS from potassium channel blocker-treated CIA rats have decreased pathogenic phenotypes}

Fourteen days after disease onset, rats with CIA were killed, and FLS were collected from individual rats. FLS isolated from either of the monotherapy or combined therapy treatment groups were significantly less invasive ex vivo than FLS from vehicle-treated rats with CIA, with no differences observed between the three potassium channel blocker treatment groups (Fig. 6a). We previously showed that the level of $\mathrm{KCa} 1.1 \alpha$ expression is directly correlated with FLS invasion and that increasing channel expression increases FLS invasion and decreasing channel expression decreases FLS invasion [17]. We sought to extend this finding in vivo and determined if KCa1.1 expression is correlated with disease severity in CIA. We stained FLS from rats with CIA from each treatment group for $\mathrm{KCa} 1.1 \alpha$ expression and found that FLS from vehicle-treated rats with CIA had significantly higher $\mathrm{KCa} 1.1 \alpha$ expression ex vivo than FLS isolated from rats with CIA treated with ShK-186, IbTX, or both ShK-186 and IbTX (Fig. 6b). Furthermore, through linear regression analyses comparing CIA rat clinical scores with each rat's FLS KCa1.1 $\alpha$ expression, we found that KCa1.1 $\alpha$ expression by FLS ex vivo was directly correlated with the disease severity clinical score of the rat from which the FLS were isolated, with an $r$ value of 0.605 (Fig. 6c).

\section{Potassium channel blockers alter T cell populations in CIA rats}

Rats with CIA were killed 14 days after disease onset; draining inguinal lymph nodes were collected; and the populations of $\mathrm{T}$ cells were examined using flow cytometry. We found that neither ShK-186 nor IbTX, alone or in combination, altered the total percentage of $\mathrm{T}$ cells, as determined by CD3 expression (Fig. 7a) or the percentage of activated $\mathrm{T}$ cells $\left(\mathrm{CD}^{+} \mathrm{CD} 25^{+}\right.$cells) (Fig. $\left.7 \mathrm{~b}\right)$, compared with vehicle-treated CIA rats. However, the proportion of memory $\mathrm{T}$ cells $\left(\mathrm{CD}^{+} \mathrm{CD} 45 \mathrm{RC}^{+}\right)$was reduced in the inguinal lymph nodes collected from rats with CIA that were treated with IbTX or both ShK-186 and IbTX compared with those of vehicle-treated CIA rats (Fig. 7c). We also found that the percentage of $\mathrm{T}$ cells that were $\mathrm{CD} 4^{+}$ was increased in the CIA rats treated with both ShK-186 and IbTX (Fig. 7d) compared with those of vehicle-treated rats, though the percentage of $\mathrm{CD} 4^{+} \mathrm{T}$ cells that were $\mathrm{CD}^{2} 5^{+}$or $\mathrm{CD} 45 \mathrm{RC}^{+}$was not different between groups (Fig. 7e and f). Furthermore, the percentage of T cells that were $\mathrm{CD}^{+}$was significantly increased in the inguinal 


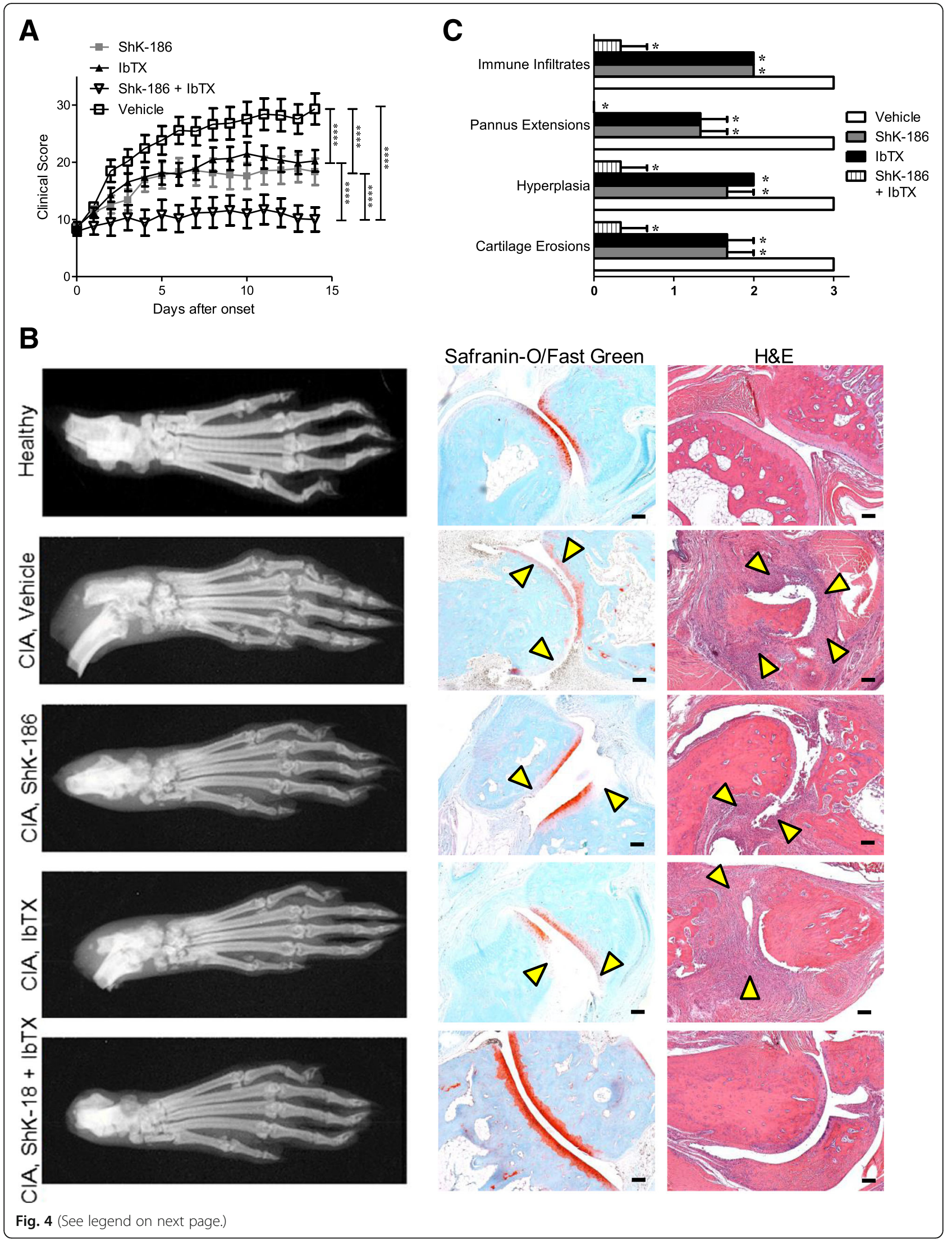


(See figure on previous page.)

Fig. 4 Kv1.3 and KCa1.1 blockers synergize to reduce disease severity in collagen-induced arthritis (CIA). a Clinical scores of rats with CIA treated with vehicle (open squares), iberiotoxin (IbTX; black triangles), ShK-186 (gray squares), or both IbTX and ShK-186 (open triangles) every other day (EOD) starting at disease onset. Data are presented as mean \pm SEM ( $n=11$ or 12 rats per group). $\mathbf{b}$ Left: X-rays of hind paws from a healthy rat and from rats with CIA treated with vehicle, IbTX, ShK-186, or both IbTX and ShK-186 EOD for 14 days after disease onset. Center and right: Safranin O/Fast Green staining (center) and H\&E staining (right) of tissue sections of hind paw joints of a healthy rat and of rats in each treatment group. Arrows indicate areas of cartilage erosions (Safranin O/Fast Green) or hyperplasia (H\&E). Scale bar $=100 \mu m$. c Scoring of disease parameters from tissue sections of paws from rats of each treatment group ( $n=3$ rats per group). ${ }^{*} p<0.05,{ }^{* * *} p<0.0001$

lymph nodes of rats with CIA treated with ShK-186, IbTX, or both ShK-186 and IbTX (Fig. 7g). Rats with CIA treated with IbTX had significantly fewer $\mathrm{CD} 8^{+} \mathrm{T}$ cells that were activated $\left(\mathrm{CD} 25^{+}\right)$or memory $\left(\mathrm{CD} 45 \mathrm{RC}^{+}\right)$cells than those of vehicle-treated CIA rats (Fig. $7 \mathrm{~h}$ and i). Approximately $1 \%$ of the $\mathrm{T}$ cells were $\mathrm{CD} 4^{+} \mathrm{CD}^{+}$and were significantly reduced in the lymph nodes of CIA rats treated with both ShK-186 and IbTX, compared with those treated with vehicle (Fig. 7j). The activation state (CD25 expression) of these cells was unchanged between treatment groups (Fig. 7k), though there were significantly fewer of these cells with a memory phenotype $\left(\mathrm{CD} 45 \mathrm{RC}^{+}\right)$in rats with

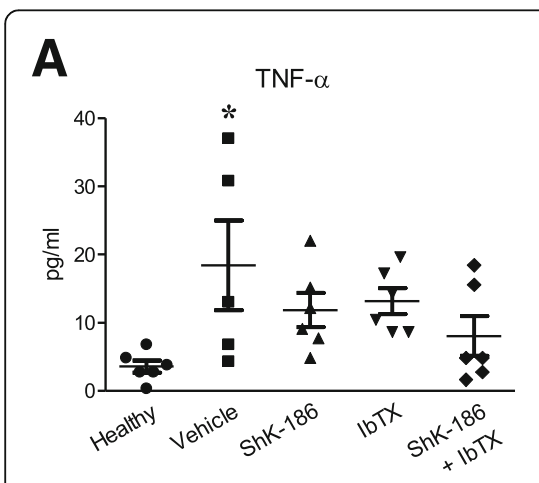

D

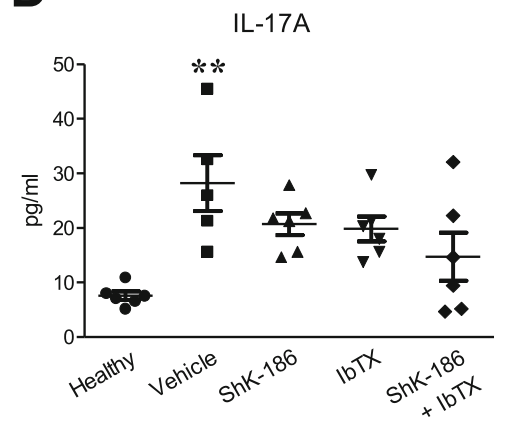

G

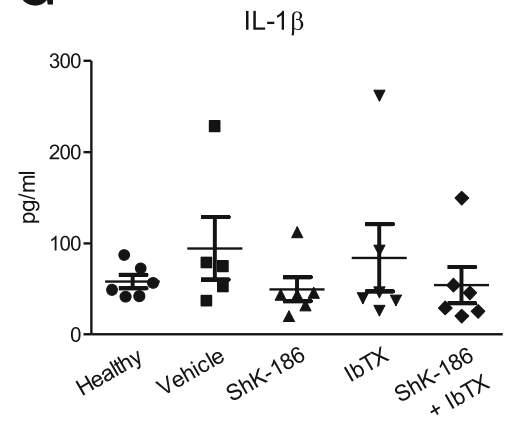

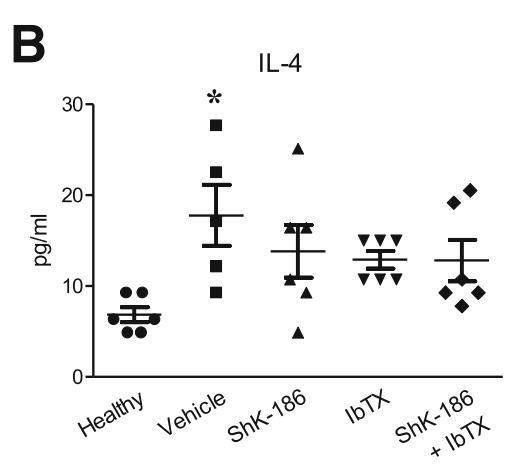

E

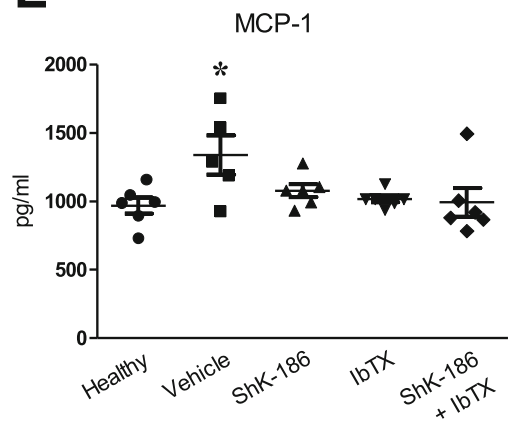

H

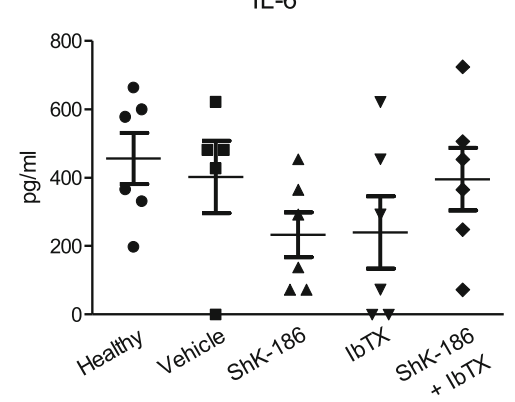

C IL-12

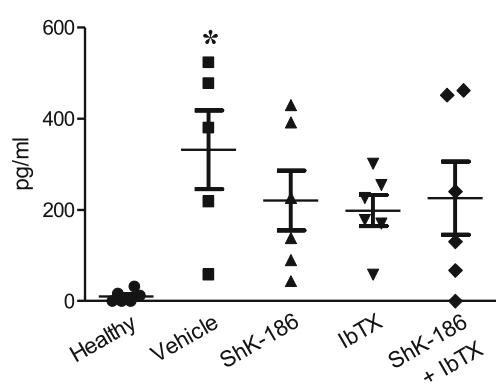

$\mathbf{F}$

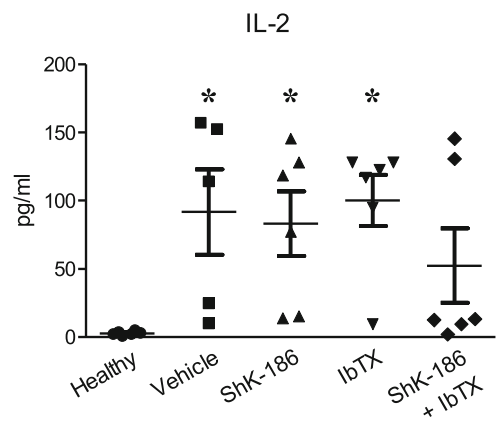

I

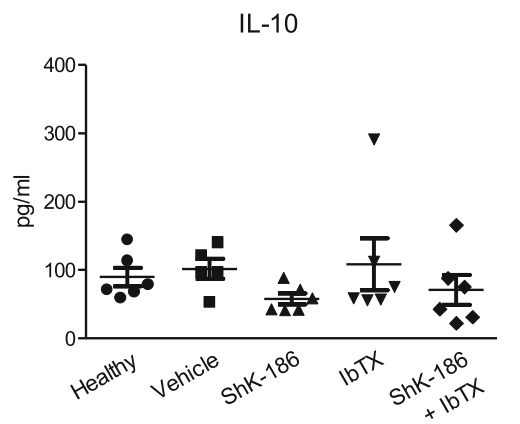

Fig. 5 Potassium channel blockers alter serum cytokines in collagen-induced arthritis (CIA). a-i Serum concentrations of tumor necrosis factor (TNF)-a, interleukin (IL)-4, IL-12, IL-17A, monocyte chemoattractant protein (MCP)-1, IL-2, IL-1 3 , IL-6, and IL-10 from healthy rats or rats with CIA treated with vehicle, ShK-186, iberiotoxin (IbTX), or both ShK-186 and IbTX every other day for 14 days after disease onset. Data are presented as mean $\pm \operatorname{SEM}\left(n=5\right.$ or 6 rats per group). ${ }^{*} p<0.05$ 


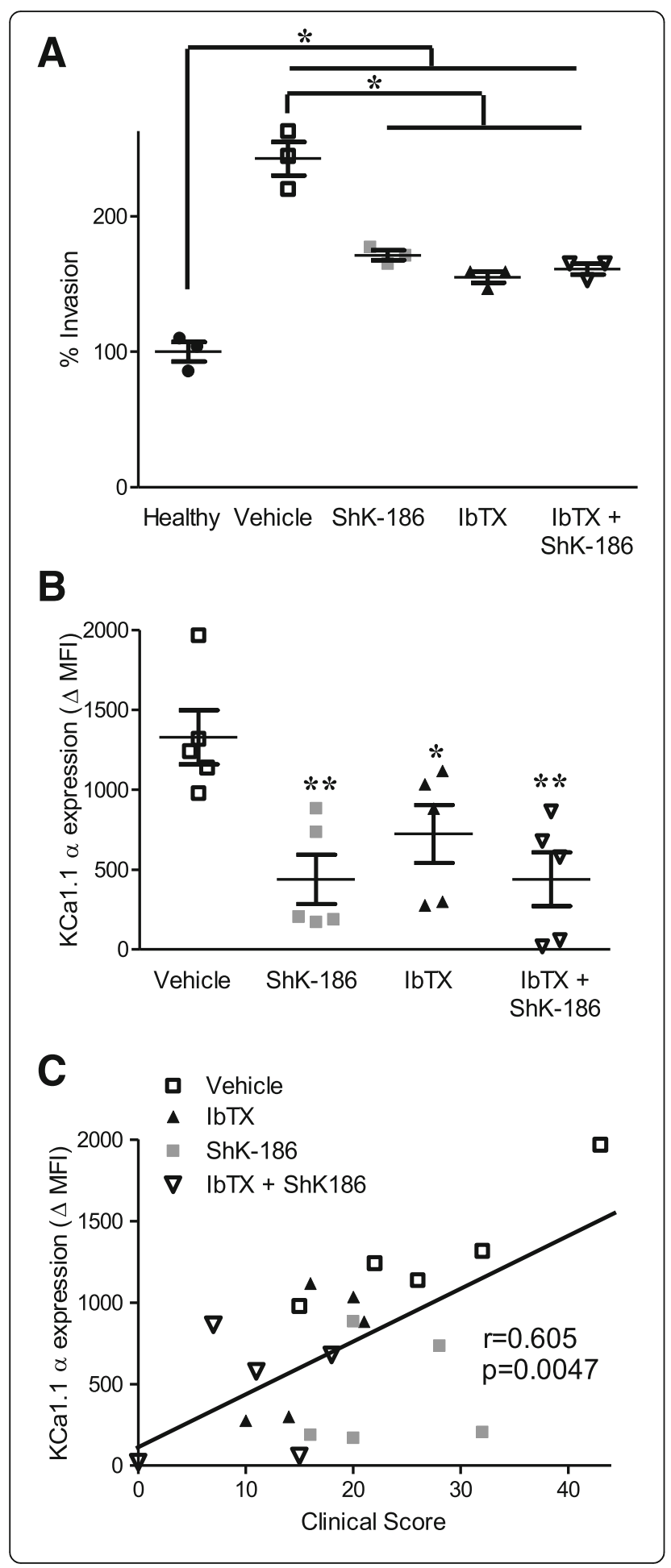

Fig. 6 Fibroblast-like synoviocytes (FLS) from collagen-induced arthritis $(\mathrm{C} \mid \mathrm{A})$ rats treated with potassium channel blockers have reduced pathogenic phenotypes ex vivo. a Invasion through Matrigel-coated Transwell inserts of FLS isolated from healthy rats or from rats with CIA treated with either vehicle, ShK-186, iberiotoxin (IbTX), or ShK-186 and IbTX every other day (EOD) for 14 days after disease onset. Data are presented as mean \pm SEM ( $n=3$ FLS donors per group). b KCa1.1 a expression by FLS isolated from healthy rats and from rats with CIA treated with vehicle, ShK-186, IbTX, or ShK186 and IbTX EOD for 14 days after disease onset. Data are presented as mean \pm SEM ( $n=5$ FLS donors per group). c Data from (b) plotted against the clinical scores on the 14th day after disease onset of the rats with CIA from which the FLS were isolated, along with a linear regression plot. ${ }^{*} p<0.05,{ }^{*} p<0.01$

CIA treated with IbTX or ShK-186 than in vehicle-treated CIA rats (Fig. 7l). Interestingly, a large proportion of $\mathrm{T}$ cells from vehicle-treated CIA rats were $\mathrm{CD} 4^{-} \mathrm{CD} 8^{-}$. This proportion was reduced in CIA rats treated with IbTX or both ShK-186 and IbTX (Fig. 7m). CD25-expressing $\mathrm{CD} 4^{-} \mathrm{CD}^{-} \mathrm{T}$ cells were increased in the CIA rats treated with IbTX or both ShK-186 and IbTX (Fig. 7n), and the percentage of $\mathrm{CD} 45 \mathrm{RC}$-expressing $\mathrm{CD}^{-}{ }^{-} \mathrm{CD} 8^{-} \mathrm{T}$ cells was also reduced in the CIA rats treated with both ShK-186 and IbTX (Fig. 7o).

\section{A combined therapy of Kv1.3 and KCa1.1 blockers is more efficacious than monotherapies in treating PIA}

To further confirm that a combinatorial therapy of Kv1.3 and KCa1.1 blockers is more efficacious at reducing disease severity than monotherapies, we tested the Kv1.3 blocker ShK-186, the KCa1.1 blocker paxilline, or both ShK-186 and paxilline in treating PIA, with treatment starting after disease onset. Similar to the results with CIA, rats with PIA treated with vehicle developed a significant amount of paw inflammation with average scores of $21 \pm 2$ (Mean \pm SEM), whereas those treated with either monotherapies of ShK-186 or paxilline had significantly fewer inflamed joints with scores of $11 \pm 2$ and $10 \pm 2$, respectively, an approximately $50 \%$ reduction in disease severity. However, rats with PIA treated with both ShK-186 and paxilline had even fewer inflamed joints than monotherapy-treated rats, with clinical scores of $6 \pm 1$, an approximately $70 \%$ reduction in disease severity (Fig. 8a).

Twenty-one days after disease onset, rats with PIA were killed, and FLS were isolated from ankle and toe joints of each rat. Invasion through Matrigel indicated that FLS from the potassium channel blocker-treated PIA rats were significantly less invasive than FLS isolated from vehicle-treated PIA rats (Fig. 8b). Paws were collected, and bone damage was assessed on $\mathrm{x}$-rays. Similar to our results with CIA, rats with PIA treated with vehicle exhibited a significant amount of bone erosion around the synovial joints, which was reduced in the 


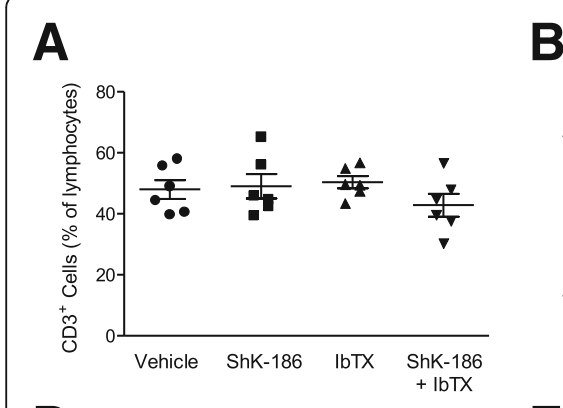

D
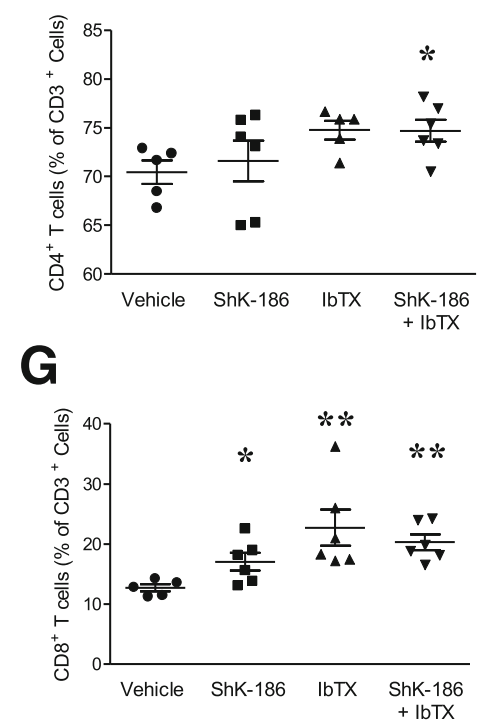

J

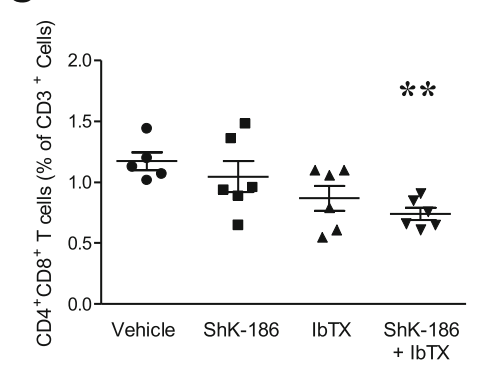

M

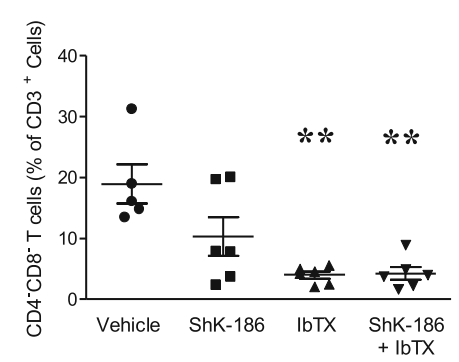

B

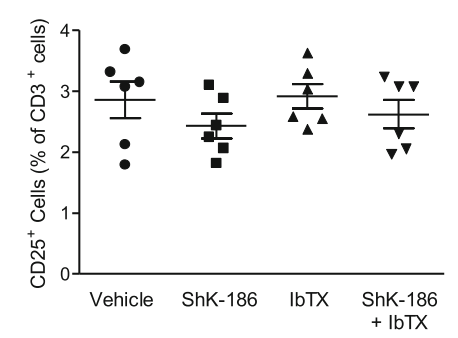

E

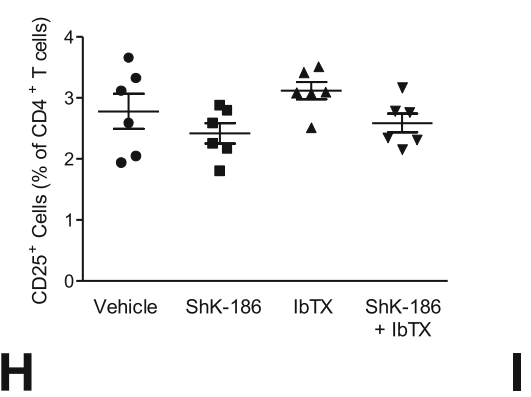

I
F
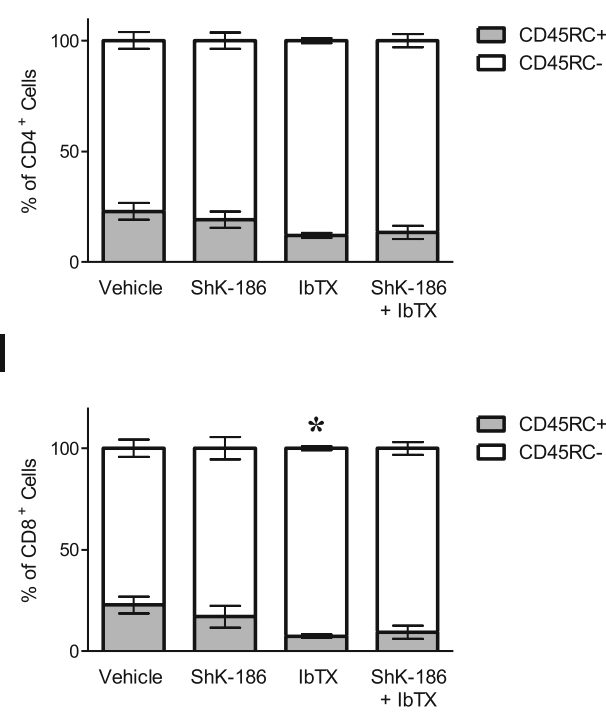

L

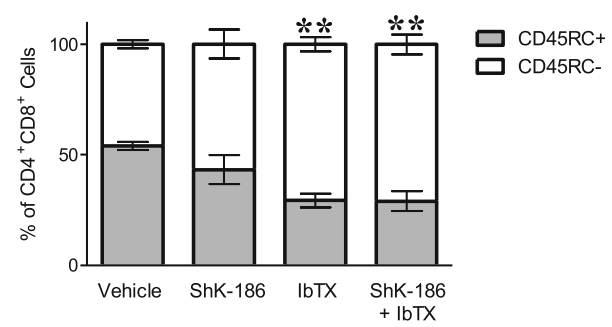

0

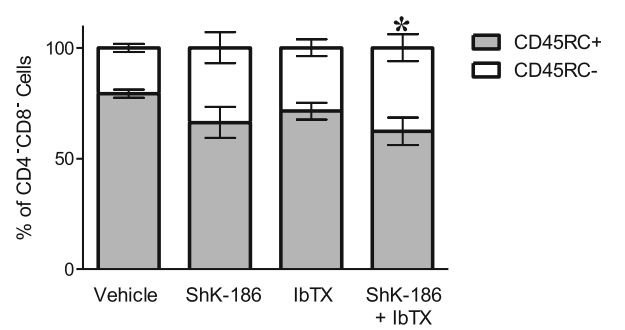

Fig. $7 \mathrm{~T}$ cell populations are altered in rats with collagen-induced arthritis (CIA) treated with potassium channel blockers. a-o Expression of CD3, CD4, CD8, CD25, and CD45RC of inguinal lymph node cells of rats with CIA treated with vehicle, ShK-186, iberiotoxin (IbTX), or ShK-186 and IbTX every other day for 14 days after disease onset ( $n=6$ rats per group). ${ }^{*} p<0.05,{ }^{* *} p<0.01$ 


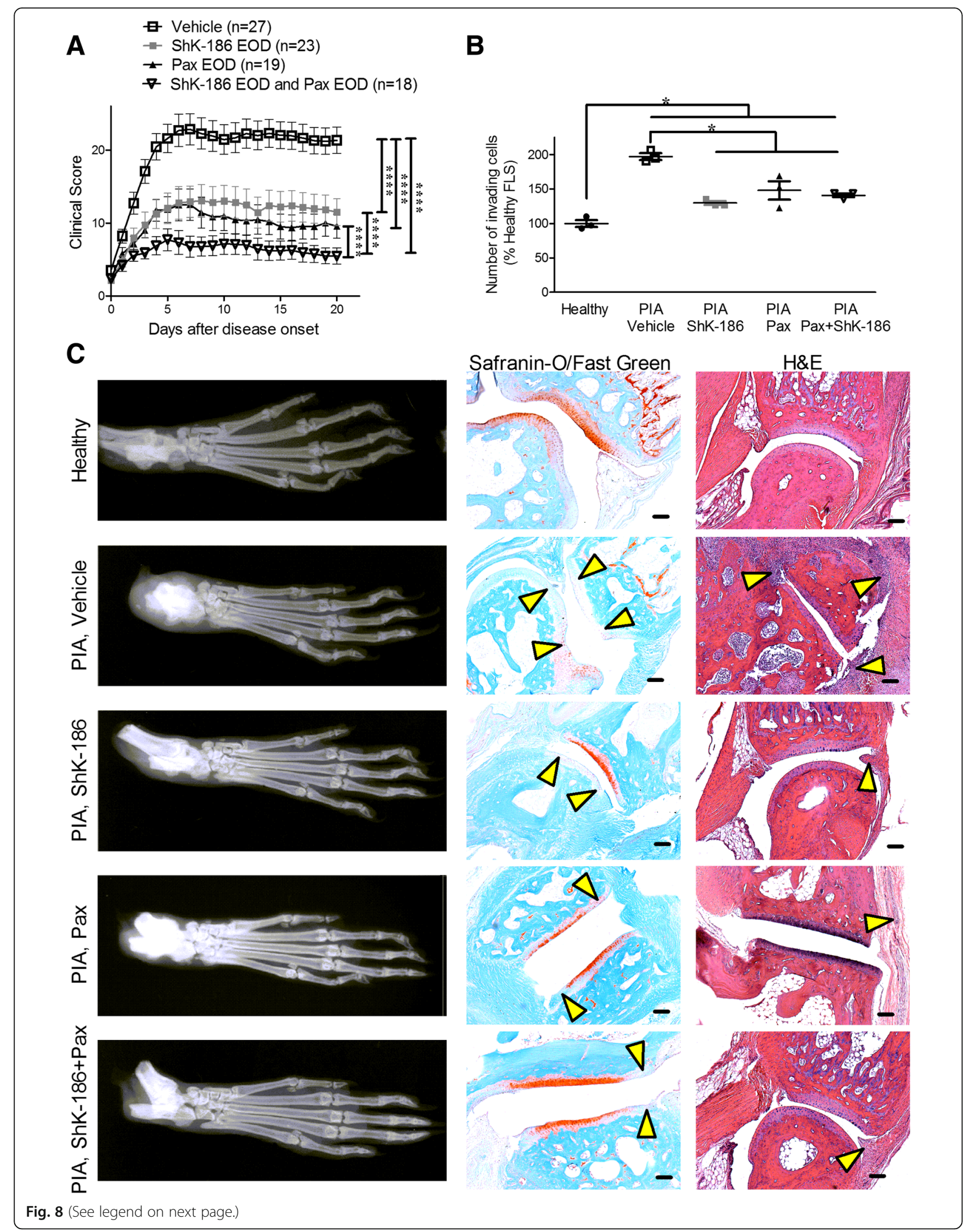


(See figure on previous page.)

Fig. $8 \mathrm{KCa} 1.1$ and Kv1.3 blockers work in tandem to reduce disease severity in pristane-induced arthritis (PIA). a Clinical scores of paw inflammation in rats with PIA treated with vehicle (open squares), paxilline (Pax; black triangles), ShK-186 (gray squares), or both paxilline and ShK-186 (open triangles) every other day for 21 days after disease onset. Data are presented as mean \pm SEM ( $n=18-27$ rats per group). $\mathbf{b}$ Ex vivo invasiveness of fibroblast-like synoviocytes (FLS) isolated from healthy rats and from rats with PIA treated with vehicle, paxilline, ShK-186, or both paxilline and ShK-186. Data are presented as mean \pm SEM, $N=3$ FLS donors per group. $\mathbf{c}$ Left, example X-rays of hind paws of a healthy rat and from rats with PIA treated with vehicle, paxilline, ShK-186, or paxilline and ShK-186 every other day for 21 days after disease onset. Center and right: Safranin O/Fast Green staining (center) and H\&E staining (right) of tissue sections of hind paw joints from a healthy rat and of rats from each treatment group. Arrows indicate areas of cartilage erosions (Safranin O/Fast Green) or hyperplasia (H\&E). Scale bar $=100 \mu \mathrm{m} .{ }^{*} p<0.05,{ }^{* * * *} p<0.0001$

potassium channel blocker-treated rats (Fig. 8c). Safranin $\mathrm{O} /$ Fast Green staining and H\&E staining of paw joints indicated that cartilage damage and immune infiltrates were reduced in the monotherapy-treated PIA rats, and were even further reduced in the combined therapy-treated PIA rats (Fig. 8c).

\section{Discussion}

In this study, we show that FLS from Lewis rats with the CIA model of RA influence the function of Lewis rat $\mathrm{T}_{\mathrm{EM}}$ cells, and vice versa, and that the major potassium channels expressed by CIA-FLS and by $\mathrm{CD} 4^{+} \mathrm{T}_{\mathrm{EM}}$ cells regulate these interactions. These findings are summarized in Fig. 9, where they are shown within the context of previous studies showing the role of KCa1.1 in mediating FLS invasion through modulation of $\beta_{1}$-integrins and Kv1.3 in regulating calcium-mediated T cell activation $[7,16]$. We also show that a combined therapy of potassium channel blockers targeting KCa1.1 expressed by FLS and Kv1.3 expressed by $\mathrm{T}_{\mathrm{EM}}$ cells work in tandem to reduce disease severity in rat models of RA with more efficacy than monotherapy treatments. Together, these data define the importance of the potassium channels of FLS and $\mathrm{T}_{\mathrm{EM}}$ cells as regulators of disease in rat models of RA and demonstrate the value of KCa1.1 and Kv1.3 channel blockers as potential therapeutics for RA.

We used FLS isolated from Lewis rats with CIA to examine their in vitro interactions with Lewis rat $\mathrm{T}_{\mathrm{EM}}$ cells in this study. Others have used human FLS isolated from patients with RA and examined their interactions with $\mathrm{T}$ cells isolated from peripheral blood of healthy volunteers with superantigens used to stimulate $\mathrm{T}$ cells

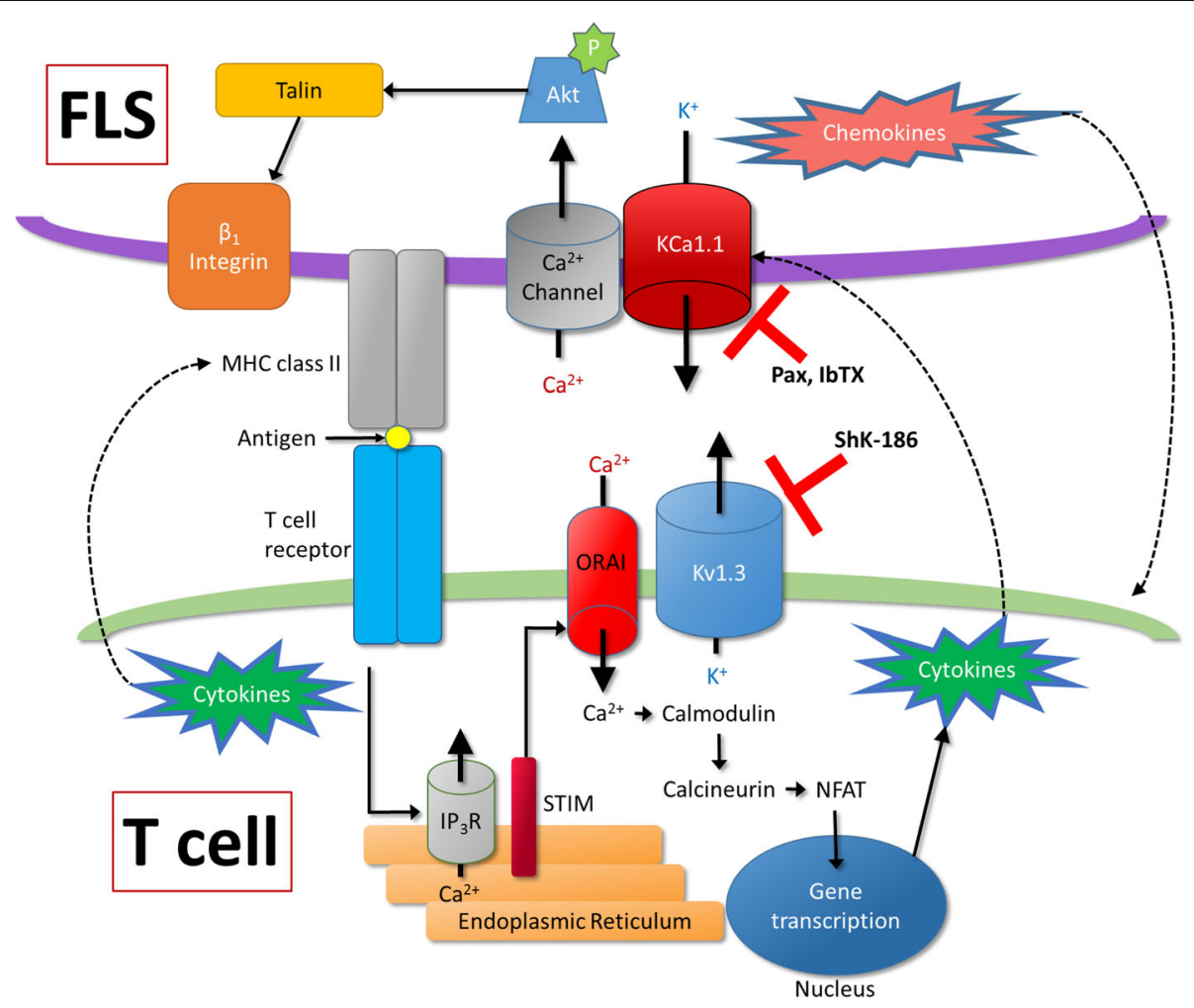

Fig. 9 Schematic summarizing the model by which fibroblast-like synoviocytes (FLS) and T cells interact, within the context of previous studies showing the role of KCa1.1 in regulating integrin-mediated invasion in FLS and Kv1.3 in regulating calcium-mediated T cell activation [7, 16] 
[23-26], or they have used antigen-specific T cell hybridomas developed from transgenic mice expressing a particular human MHC class II allele [26]. Although using human cells is ideal for the study of disease processes in RA, the mixing of FLS and T cells from different individuals or species could lead to the observation of phenotypes that would not be observed naturally in patients with RA. For this reason, and because of the difficulty in obtaining both FLS and sufficient numbers of $\mathrm{T}_{\mathrm{EM}}$ cells from the same individuals, we used FLS and $\mathrm{T}_{\mathrm{EM}}$ cells from inbred Lewis rats. The choice of model species is carefully made because ion channel phenotype, function, and response to pharmacological agents vary between species [32]. We chose rats for this work because the phenotype and function of KCa1.1 in FLS are conserved between humans and rats, as are the phenotype and function of Kv1.3 in T cell subsets in these two species. In contrast, mouse and human $\mathrm{T}$ cells diverge in potassium channel expression [32], precluding the use of mice in the present study.

The conditioned medium from activated $\mathrm{T}_{\mathrm{EM}}$ cells induced an increase in $\mathrm{MHC}$ class II and $\mathrm{KCa} 1.1 \alpha$ protein expression in CIA-FLS. In addition, CIA-FLS invaded through Matrigel toward the conditioned medium, indicating that activated $\mathrm{T}_{\mathrm{EM}}$ cells secrete cytokines which increase the pathogenic features of FLS and chemokines which direct FLS motility. Because the $\mathrm{T}_{\mathrm{EM}}$ cells used in these experiments are Th1 cells [10], the cytokines responsible for these changes in FLS phenotype were likely IFN- $\gamma$ or TNF- $\alpha$, or a combination of both. IFN- $\gamma$ is the only known cytokine to induce MHC class II expression in FLS [53], whereas both IFN- $\gamma$ and TNF- $\alpha$ enhance FLS invasion [28-30]. It is likely that one or both of these cytokines induced FLS invasion. These results may also indicate that blocking Kv1.3 can be a novel way to locally interfere with TNF- $\alpha$ production, a key disease mediator, without systemically suppressing a patient's immune system.

The mechanism by which KCa1.1 $\alpha$ expression is regulated in FLS, and how it becomes upregulated during disease, is unknown. However, it is likely through a cytokine-mediated pathway, because our data show that the medium of stimulated $\mathrm{T}_{\mathrm{EM}}$ cells can induce its upregulation in CIA-FLS and that recombinant proinflammatory cytokines (IFN- $\gamma$, TNF- $\alpha$, and IL-1 $\beta$ ) induce KCa1.1 $\alpha$ upregulation by RA-FLS. Interestingly, the osteoclastogenic cytokine RANKL, which is secreted by RA-FLS [54], also induces KCa1.1 $\alpha$ upregulation in RA-FLS, leading to a possible autocrine or paracrine regulation of KCa1.1. Furthermore, Kv1.3 blockade on $\mathrm{T}_{\mathrm{EM}}$ cells prevents secretion of some proinflammatory cytokines by RA synovial fluid $\mathrm{T}_{\mathrm{EM}}$ cells [6]. The conditioned medium of $\mathrm{T}_{\mathrm{EM}}$ cells stimulated in the presence of the Kv1.3 blocker ShK-186 did not alter FLS invasion,
KCa1.1 $\alpha$ expression, or MHC class II expression compared with conditioned medium from unstimulated $\mathrm{T}_{\mathrm{EM}}$ cells. This further verifies that the cytokines secreted by $\mathrm{T}_{\mathrm{EM}}$ cells alter FLS phenotypes and that Kv1.3 can regulate these phenotypes.

IFN- $\gamma$-stimulated CIA-FLS induced the migration of $\mathrm{T}_{\mathrm{EM}}$ cells toward them, and blocking KCa1.1 on CIA-FLS reduced this effect. This indicates that upon IFN- $\gamma$ stimulation, CIA-FLS secrete chemokines that influence $\mathrm{T}$ cell migration. CIA and RA-FLS are known to produce a variety of $\mathrm{T}$ cell chemoattractants upon cytokine stimulation, including CXCL10 [46, 49], fractalkine [48], IL-6, IL-8, CCL2, CCL5, and CXCL12 [47]. KCa1.1 blockade prevents FLS from secreting the chemokines IL-8 and VEGF, but not IL-6 [19]. It is therefore likely that KCa1.1 block also prevents FLS secretion of one or more $\mathrm{T}$ cell chemoattractants. In order to determine which particular chemokines are responsible for the FLS-induced $\mathrm{T}$ cell migration, it is necessary to first identify the complete milieu of chemokines secreted by IFN- $\gamma$-stimulated FLS and determine which of these chemokines are regulated by KCa1.1.

We found that IFN- $\gamma$ induced an increase in MHC class II protein expression on CIA-FLS, in concordance with previous studies in RA-FLS [23, 26, 53]. Interestingly, cotreatment with the $\mathrm{KCa} 1.1$ blocker paxilline reduced the plasma membrane expression of MHC class II molecules, but not the total amount of MHC class II protein present in FLS. These data show that KCa1.1 activity is not necessary for IFN- $\gamma$ to induce MHC class II protein production, but it is required for its localization to the plasma membrane. The mechanism underlying this observation has yet to be determined, but it may involve $\mathrm{KCa} 1.1$ serving as a regulator of protein and vesicle trafficking, cytoskeletal rearrangements, or membrane fluidity and turnover within FLS, which could all result in this channel regulating protein expression at the cell's surface.

Though stimulating FLS with IFN- $\gamma$ has been a widely studied means to induce the antigen-presenting phenotype of FLS [22-24, 26, 53], the relevance of FLS antigen presentation and IFN- $\gamma$ to disease severity and the pathophysiology of RA is subject to debate. Indeed, TNF- $\alpha$, and not IFN- $\gamma$, is generally seen as the prototypical driver of inflammation in RA, and these two cytokines exhibit a mutual antagonism on their effects on FLS phenotypes, including MHC class II protein expression [53]. IFN- $\gamma$ also reduces IL- $1 \beta$-induced matrix metalloprotease secretion in FLS, limiting their ability to degrade cartilage [55]. IFN- $\gamma$ receptor-knockout mice, or mice treated with neutralizing antibodies against IFN- $\gamma$, have accelerated onset of CIA, higher disease severity during CIA, and increased Th17 cells [56, 57]. Furthermore, recombinant IFN- $\gamma$ progressed through several 
clinical trials as a potential RA therapy [58-60]. However, IFN- $\gamma$ and its receptor expression are upregulated in the synovium of patients with RA compared with patients with osteoarthritis [61], and IFN- $\gamma$ promotes FLS motility and invasion [29, 30]. Therefore, it remains to be determined how relevant these observations are within the actual disease state. Furthermore, cytokine receptors can have converging signaling pathways and other proinflammatory cytokines that activate the same signaling cascades as those downstream of the IFN- $\gamma$ receptor and may induce the same phenotypes observed in FLS following IFN- $\gamma$ stimulation [62].

Determining if FLS can present antigen on MHC class II and stimulate $\mathrm{CD} 4^{+} \mathrm{T}$ cells in vivo and thereby serve as nontraditional professional antigen-presenting cells may reveal important information regarding inflammation in RA, because it would reveal FLS as an in situ activator of $\mathrm{T}$ cells at a site of inflammation. This could have major implications regarding the importance of FLS and IFN- $\gamma$ in initiating inflammation in $\mathrm{RA}$, because it is possible that localized increases in IFN- $\gamma$ levels, perhaps from inflammation due to an infection or physical insult to the joint, could activate FLS antigen presentation and therefore initiate $\mathrm{T}$ cell-driven inflammation.

We found that several cytokines were elevated in the serum of vehicle-treated rats with CIA compared with healthy rats and that ShK-186 and IbTX normalized their levels. These included IL-4, IL-12, IL-17A, MCP-1, and TNF- $\alpha$. Given that blocking Kv1.3 on $\mathrm{T}_{\mathrm{EM}}$ cells reduces their secretion of cytokines, it was expected that ShK-186 treatments would reduce circulating cytokine levels. The mechanisms by which IbTX reduced these cytokines is less clear, though it is possible that inhibiting FLS indirectly causes a reduction in T cell cytokine secretion. Several cytokines were also found in decreased concentrations in the serum of rats with CIA, including fractalkine, leptin, and RANTES, among others. Fractalkine and RANTES are increased in the serum of patients with RA, and their inhibition decreases disease severity in mouse CIA and rat adjuvant-induced arthritis, respectively [63-66]. The mechanisms by which these cytokines decrease in rat CIA remains unknown. Leptin is also associated with RA and is increased in the serum of patients with RA. However, its role in rodent models of RA is less clear and may be decreased in the serum during mouse models of RA [67]. Our data suggest that a similar trend exists in rat models of RA, and overall our data indicate potential divergences in the pathogenesis between RA and its animal models.

We found that rats with either PIA or CIA treated with a Kv1.3 blocker or a KCa1.1 blocker had reduced disease severity, in agreement with previous studies [6, 17]. However, tandem therapies of Kv1.3 and KCa1.1 blockers were even more beneficial than the monotherapies, indicating the value of directly targeting both $\mathrm{T}_{\mathrm{EM}}$ cells and FLS as a novel and potent therapeutic approach to treating RA. Furthermore, because the combined therapy of Kv1.3 and KCa1.1 blockers was more beneficial than the monotherapies, it can be inferred that the monotherapies do not have large downstream effects on the reciprocal cell type through limiting either the $\mathrm{T}_{\mathrm{EM}}$ cell-induced increase in FLS pathogenicity when blocking Kv1.3 or limiting the FLS-induced increase in $\mathrm{T}_{\mathrm{EM}}$ cell pathogenicity when blocking $\mathrm{KCa}$.1. This also implies that both FLS and $\mathrm{T}_{\mathrm{EM}}$ cells drive disease progression, as opposed to one cell type inducing the pathogenic phenotype of the other.

However, through examining the ex vivo invasiveness of FLS isolated from rats of each treatment group, we found that FLS from arthritic rats treated with ShK-186 had reduced invasion compared with FLS from vehicle-treated animals. FLS do not express Kv1.3, and ShK-186 does not block KCa1.1 and does not have an effect on FLS phenotypes [19, 31, 32]. This indicates that our observations in the present study were not a result of ShK-186 directly affecting FLS. Therefore, our data show that even though the FLS were not directly inhibited by ShK-186, the decrease in $\mathrm{T}_{\mathrm{EM}}$ cell pathogenicity did have at least some downstream effects on FLS in vivo. Similarly, $\mathrm{T}_{\mathrm{EM}}$ cells do not express $\mathrm{KCa1.1}$, and paxilline and IbTX do not block Kv1.3 [7, 33, 34]. Therefore, the effects of KCa1.1 blockers in ameliorating disease in PIA and CIA were not due to directly inhibiting $\mathrm{T}_{\mathrm{EM}}$ cells.

The populations of $\mathrm{T}$ cells within the draining inguinal lymph nodes of rats with CIA treated with potassium channel blockers were altered compared with those of vehicle-treated rats. For example, those treated with ShK-186, IbTX, or both ShK-16 and IbTX had an increase in the proportion of $\mathrm{CD}^{+} \mathrm{T}$ cells compared with those from vehicle-treated rats with CIA. $\mathrm{CD}^{+} \mathrm{T}$ cells may have a protective role in RA [68], and our data suggest that $\mathrm{CD} 8^{+} \mathrm{T}$ cells are correlated with a decreased disease burden. We also found large differences in the proportion of $\mathrm{CD} 4^{-} \mathrm{CD} 8^{-} \mathrm{T}$ cells in the draining inguinal lymph nodes of rats with CIA, in which those treated with IbTX in the presence or absence of ShK-186 had dramatically reduced populations of these cells compared with vehicle-treated animals. Interestingly, although the proportion of these cells were decreased in these rats, they expressed more of the activation marker CD25 than vehicle-treated rats with CIA. The role of $\mathrm{CD} 4^{-} \mathrm{CD}^{-} \mathrm{T}$ cells in RA and the roles of Kv1.3 and KCa1.1 in them is not well understood. Overall, our studies suggest that both Kv1.3 and KCa1.1 blockers 
affect $\mathrm{T}$ cell populations in CIA, though the mechanisms by which they do so, along with the roles of some of these cells, are yet to be investigated.

The ex vivo invasion of FLS is directly correlated with disease severity in patients with RA [37, 69, 70], and we found that FLS isolated from rats with PIA or CIA that were treated with Kv1.3 or KCa1.1 blockers, alone or in combination, exhibited reduced ex vivo invasion compared with vehicle-treated rats. These results agree with previous findings regarding FLS invasion as a measure of disease severity and joint destruction [69]. However, although the rats with PIA or CIA that were treated with a combined therapy of KCa1.1 and Kv1.3 blockers had reduced disease severity compared with monotherapy-treated rats, the ex vivo invasiveness was approximately the same. This may be due to limitations of the technique used to measure invasion, because the method we used involved measuring the number of cells that invaded through Matrigel at a single time point and did not account for differences in their rates of invasion.

\section{Conclusions}

Overall, these studies provide further insights into the role of FLS and T cell interactions during RA and the importance of the potassium channels these cells express as mediators of these interactions. We also validated a novel therapeutic approach to treating RA by simultaneously inhibiting FLS and $\mathrm{T}_{\mathrm{EM}}$ cells through targeting the predominant potassium channels by which these cells are regulated. In doing so, we further validated the central role of FLS and $\mathrm{T}_{\mathrm{EM}}$ cells in the pathogenesis of RA and the importance of KCa1.1 and Kv1.3 in driving disease progression.

\section{Additional files}

Additional file 1: Table S1. Serum chemical analyses of healthy rats and rats with CIA treated with vehicle, IbTX, ShK-186, or IbTX and ShK186 every other day. Data are shown as mean (SD). $n=5$ rats per group. (DOCX $17 \mathrm{~kb})$

Additional file 2: Table S2. Serum cytokine analyses of healthy rats and rats with CIA treated with vehicle, IbTX, ShK-186, or IbTX and ShK-186 every other day. Data are shown as mean (SD). $n=5$ or 6 rats per group. (DOCX $16 \mathrm{~kb})$

\section{Abbreviations}

APC: Allophycocyanin; CFSE: Carboxyfluorescein succinimidyl ester; CIA: Collagen-induced arthritis; FLS: Fibroblast-like synoviocytes; IbTX: Iberiotoxin; ICAM-1: Intercellular adhesion molecule 1; IFN: Interferon; KCa1.1: Large-conductance calcium-activated potassium channel 1.1; Kv1.3: Voltage-gated potassium channel 1.3; MHC: Major histocompatibility complex; Pax: Paxilline; PIA: Pristane-induced arthritis; RA: Rheumatoid arthritis; RANKL: Receptor activator of nuclear factor $\mathrm{KB}$ ligand; $\mathrm{T}_{\mathrm{EM}}$ cell: Effector memory T cell; TNF: Tumor necrosis factor

\section{Funding}

This work was supported by National Institutes of Health award NS073712 (to CB and MWP) and Arthritis Foundation award 6483 (to CB and MWP). MRT was supported by T32 awards GM088129, Al053831, and HL007676 and F31 award AR069960 from the National Institutes of Health. The Cytometry and Cell Sorting, Mouse Phenotyping, and Pathology \& Histology cores at Baylor College of Medicine are supported in part by funding from the National Institutes of Health (grants HG006348, RR024574, and CA125123) and the Dan L Duncan Comprehensive Cancer Center at Baylor College of Medicine.

\section{Availability of data and materials}

The data supporting the authors' conclusions are included in the article.

\section{Authors' contributions}

MRT and CB designed the study. MWP, SSC, TL, and PSG provided critical reagents. MRT, MWP, and CB performed experiments. MRT and CB wrote the manuscript with input from all authors. All authors read and approved the final manuscript.

\section{Ethics approval}

The experiments involving the use of rats were approved by the Institutional Animal Care and Use Committee at Baylor College of Medicine. De-identified human FLS were isolated by PSG's group after patients provided written consent for their tissues to be studied, as approved by the Institutional Review Board at the Feinstein Institute for Medical Research. Baylor College of Medicine's Institutional Review Board determined that the study of these cells did not constitute human research, because the samples were de-identified.

\section{Consent for publication}

Not applicable.

\section{Competing interests}

CB and MWP are inventors on the patent for ShK-186/dalazatide. CB and MWP are cofounders of Airmid, Inc., and sit on its board of directors. CB and MWP are investors in Kineta, Inc. The other authors declare that they have no competing interests.

\section{Publisher's Note}

Springer Nature remains neutral with regard to jurisdictional claims in published maps and institutional affiliations.

\section{Author details}

${ }^{1}$ Department of Molecular Physiology and Biophysics, Baylor College of Medicine, One Baylor Plaza, Houston, TX 77030, USA. ${ }^{2}$ Interdepartmental Graduate Program in Translational Biology and Molecular Medicine, Baylor College of Medicine, Houston, TX, USA. ${ }^{3}$ Peptides International, Inc., Louisville, KY, USA. ${ }^{4}$ Present address: Ambiopharm, Inc., North Augusta, SC, USA. ${ }^{5}$ Division of Rheumatology, Department of Medicine, Icahn School of Medicine at Mount Sinai, New York, NY, USA. 'Biology of Inflammation Center, Center for Drug Discovery, Cardiovascular Research Institute, and Dan L Duncan Comprehensive Cancer Center, Baylor College of Medicine, Houston, TX, USA.

Received: 3 September 2018 Accepted: 29 November 2018 Published online: 07 January 2019

\section{References}

1. Cope A. T cells in rheumatoid arthritis. Arthritis Res Ther. 2008;10(Suppl 1):S1.

2. Cope A, Schulze-Koops H, Aringer M. The central role of T cells in rheumatoid arthritis. Clin Exp Rheumatol. 2007;25((5 Suppl 46)):S4-11.

3. Smolen J, Aletaha D. Rheumatoid arthritis therapy reappraisal: strategies, opportunities, and challenges. Nat Rev Rheumatol. 2015;11:276-89.

4. Keyser F. Choice of biologic therapy for patients with rheumatoid arthritis: the infection perspective. Curr Rheumatol Rev. 2011;7:77-87.

5. Fasth A, Cao D, van Vollenhoven R, Trollmo C, Malmstrom V. CD28 ${ }^{\text {null }} C D 4^{+} T$ cells - characterization of an effector memory T-cell population in patients with rheumatoid arthritis. Scand J Immunol. 2004;60:199-208.

6. Beeton C, Wulff H, Standifer N, Azam P, Mullen K, Pennington M, KolskiAndreaco A, Wei E, Grino A, Counts D, et al. Kv1.3 channels are a 
therapeutic target for T cell-mediated autoimmune diseases. Proc Natl Acad Sci U S A. 2006;103(46):17414-9.

7. Chi V, Pennington M, Norton R, Tarcha E, Londono L, Sims-Fahey B, Upadhyay S, Lakey J, ladonato S, Wulff H, et al. Development of a sea anemone toxin as an immunomodulator for therapy of autoimmune diseases. Toxicon. 2012;59:529-46.

8. Wulff H, Calabresi P, Allie R, Yun S, Pennington M, Beeton C, Chandy K. The voltage-gated $\mathrm{Kv} 1.3 \mathrm{~K}^{+}$channel in effector memory $\mathrm{T}$ cells as new target for MS. J Clin Invest. 2003;111:1703-13.

9. Tarcha E, Chi V, Munoz-Elias E, Bailey D, Londono L, Upadhyay S, Norton K, Banks A, Tjong I, Nguyen $\mathrm{H}$, et al. Durable pharmacological responses from the peptide ShK-186, a specific Kv1.3 channel inhibitor that suppresses T cell mediators of autoimmune disease. J Pharmacol Exp Ther. 2012;342:642-53.

10. Matheu M, Beeton C, Garcia A, Chi V, Pangaraju S, Safrina O, Monaghan K, Uemura M, Li D, Pal S, et al. Imaging of effector memory T cells during a delayed-type hypersensitivity reaction and suppression by Kv1.3 channel block. Immunity. 2008;29:602-14.

11. Tanner M, Tajhya R, Huq R, Gehrmann E, Rodarte K, Atik M, Norton R, Pennington $\mathrm{M}$, Beeton C. Prolonged immunomodulation in inflammatory arthritis using the selective Kv1.3 channel blocker HsTX1[R14A] and its PEGylated analog. Clin Immunol. 2017;180:45-57.

12. Tarcha E, Olsen C, Probst P, Peckham D, Munoz-Elias E, Kruger J, ladonato S. Safety and pharmacodynamics of dalazatide, a Kv1.3 channel inhibitor, in the treatment of plaque psoriasis: a randomized phase $1 \mathrm{~b}$ trial. PLoS One. 2017;12:e0180762

13. Munoz-Elias E, Peckham D, Norton K, Duculan J, Cueto I, Li X, Qin J, Lustig K, Tarcha E, Odegard J, et al. Dalazatide (ShK-186), a first-in-class blocker of Kv1.3 potassium channel on effector memory T cells: safety, tolerability and proof of concept of immunomodulation in patients with active plaque psoriasis [abstract]. Arthritis Rheumatol. 2015;67(suppl 10).

14. Bottini N, Firestein G. Dualtiy of fibroblast-like synoviocytes in RA: passive responders and imprinted aggressors. Nat Rev Rheumatol. 2013;9:24-33.

15. Bartok B, Firestein G. Fibroblast-like synoviocytes: key effector cells in rheumatoid arthritis. Immunol Rev. 2010;233(1):233-55.

16. Tanner M, Pennington M, Laragione T, Gulko P, Beeton C. KCa1.1 channels regulate $\beta 1$ integrin function and cell adhesion in rheumatoid arthritis fibroblast-like synoviocytes. FASEB J. 2017;31(8):3309-20.

17. Tanner M, Hu X, Huq R, Tajhya R, Sun L, Khan F, Laragione T, Horrigan F, Gulko P, Beeton C. KCa1.1 inhibition attenuates fibroblast-like synoviocyte invasiveness and ameliorates disease in rat models of rheumatoid arthritis. Arthritis Rheumatol. 2015;67(1):96-106.

18. Pethő Z, Tanner M, Tajhya R, Huq R, Laragione T, Panyi G, Gulko P, Beeton C. Different expression of $\beta$ subunits of the KCa1.1 channel by invasive and noninvasive human fibroblast-like synoviocytes. Arthritis Res Ther. 2016;18:103.

19. Hu X, Laragione T, Sun L, Koshy S, Jones K, Ismailov I, Yotnda P, Horrigan F, Gulko P, Beeton C. KCa1.1 potassium channels regulate key proinflammatory and invasive properties of fibroblast-like synoviocytes in rheumatoid arthritis. J Biol Chem. 2012;287(6):4014-22.

20. Beeton C. KCa1.1 channels as therapeutic targets for rheumatoid arthritis. Expert Opin Ther Targets. 2017;21:1077-81.

21. Tanner M, Pennington M, Chamberlain B, Huq R, Gehrmann E, Laragione T, Gulko P, Beeton C. Targeting KCa1.1 channels with a scorpion venom peptide for the therapy of rat models of rheumatoid arthritis. J Pharmacol Exp Ther. 2018;365:227-36.

22. Boots A, Wimmers-Bertens A, Rijnders A. Antigen-presenting capacity of rheumatoid synovial fibroblasts. Immunology. 1994;82:268-74.

23. Tsai C, Diaz LJ, Singer N, Li L, Kirsch A, Mitra R, Nickoloff B, Crofford L, Fox D. Responsiveness of human $T$ lymphocytes to bacterial superantigens presented by cultured rheumatoid arthritis synoviocytes. Arthritis Rheum. 1996;39:125-36.

24. Tran C, Thacker S, Louie D, Oliver J, White P, Endres J, Urguhart A, Chung K, Fox D. Interactions of T cells with fibroblast-like synoviocytes: role of the B7 family costimulatory ligand B7-H3. J Immunol. 2008;180:2989-98.

25. Tran C, Lundy S, White P, Endres J, Motyl C, Gupta R, Wilke C, Shelden E, Chung $K$, Urguhart A, et al. Molecular interactions between $T$ cells and fibroblast-like synoviocytes: role of membrane tumor necrosis factor-a on cytokine-activated T cells. Am J Pathol. 2007;171:1588-98.

26. Tran C, Davis M, Tesmer L, Endres J, Motyl C, Smuda C, Somers E, Chung K, Urguhart A, Lundy $S$, et al. Presentation of arthritogenic peptide to antigenspecific T cells by fibroblast-like synoviocytes. Arthritis Rheum. 2007:56: 1497-506.
27. Cho C, Cho M, Min S, Kim W, Min D, Lee S, Park S, Choe J, Kim H. CD40 engagement on synovial fibroblast up-regulates production of vascular endothelial growth factor. J Immunol. 2000;164:5055-61.

28. Hot A, Zrioual S, Lenief $\mathrm{V}$, Miossec P. IL-17 and tumour necrosis factor $a$ combination induces a HIF-1a-dependent invasive phenotype in synoviocytes. Ann Rheum Dis. 2012;71:1393-401.

29. Karonitsch T, Dalwigk K, Byrne R, Niedereiter B, Cetin E, Wanivenhaus A, Scheinecker C, Smolen J, Kiener H. IFN- $\gamma$ promotes the invasive behavior of fibroblast-like synoviocytes [abstract]. Ann Rheum Dis. 2012;71(Suppl 1):A48.

30. Karonitsch T, Dalwigk K, Byrne R, Niedereiter B, Cetin E, Wanivenhaus A, Scheinecker C, Smolen J, Kiener H. IFN-y promotes fibroblast-like synoviocytes motility [abstract]. Ann Rheum Dis. 2010;69(Suppl 2):A63.

31. Beeton C, Pennington M, Norton R. Analogs of the sea anemone potassium channel blocker ShK for the treatment of autoimmune diseases. Inflamm Allergy Drug Targets. 2011;10:313-21.

32. Tanner M, Beeton C. Differences in ion channel phenotype and function between humans and animal models. Front Biosci. 2018;23:43-64.

33. Gao Y, Garcia M. Interaction of agitoxin2, charybdotoxin, and iberiotoxin with potassium channels: selectivity between voltage-gated and Maxi-K channels. Proteins. 2003;52:146-54.

34. Cidad P, Jimenez-Perez L, Garcia-Arribas D, Miguel-Velado E, Tajada S, RuizMcDavitt C, Lopez-Lopez J, Perez-Garcia M. Kv1.3 channels can modulate cell proliferation during phenotypic switch by an ion-flux independent mechanism. Arterioscler Thromb Vasc Biol. 2012;32:1299-307.

35. Aletaha D, Neogi T, Silman A, Funovits J, Felson D, Bingham C, Birnbaum N, Burmester G, Bykerk V, Cohen M, et al. Rheumatoid arthritis classification criteria: an American College of Rheumatology/European League Against Rheumatism collaborative initiative. Ann Rheum Dis. 2010;2010(69):1580-8.

36. Laragione T, Gulko P. mTOR regulates the invasive properties of synovial fibroblasts in rheumatoid arthritis. Mol Med. 2010;16(9-10):352-8.

37. Laragione T, Brenner M, Mello A, Symons M, Gulko P. The arthritis severity locus Cia5d is a novel genetic regulator of the invasive properties of synovial fibroblasts. Arthritis Rheum. 2008;58:2296-306.

38. Grissmer S, Nguyen A, Aiyar J, Hanson D, Mather R, Gutman G, Karmilowicz M, Auperin D, Chandy K. Pharmacological characterization of five cloned voltage-gated $\mathrm{K}^{+}$channels, types Kv1.1, 1.2, 1.3, 1.5, and 3.1, stably expressed in mammalian cell lines. Mol Pharmacol. 1994;45(6):1227-34.

39. Ruers T, Buurman W, van Boxtel C, van der Linden C, Kootstra G. Immunohistological observations in rat kidney allografts after local steroid administration. J Exp Med. 1987;166:1205-20.

40. Flügel A, Willem M, Berkowicz T, Wekerle H. Gene transfer into CD4 ${ }^{+} \mathrm{T}$ lymphocytes: green fluorescent protein-engineered, encephalitogenic $T$ cells illuminate brain autoimmune responses. Nat Med. 1999;5:843-7.

41. Beeton C, Chandy K. Induction and monitoring of adoptive delayed-type hypersensitivity in rats. J Vis Exp. 2007;8:325.

42. Huq R, Samuel E, Sikkema W, Nilewski L, Lee T, Tanner M, Khan F, Porter P, Tajhya R, Patel R, et al. Preferential uptake of antioxidant carbon nanoparticles by T lymphocytes for immunomodulation. Sci Rep. 2016;6:33808.

43. Koshy S, Wu D, Hu X, Tajhya R, Huq R, Khan F, Pennington M, Wulff H, Yotnda P, Beeton C. Blocking KCa3.1 channels increases tumor cell killing by a subpopulation of human natural killer lymphocytes. PLoS One. 2013;8:e76740.

44. Griffiths M, Cremer M, Harper D, McCall S, Cannon G. Immunogenetics of collagen-induced arthritis in rats: both $\mathrm{MHC}$ and non-MHC gene products determine the epitope specificity of immune response to bovine and chick type II collagens. J Immunol. 1992;149:309-16.

45. Brenner M, Meng H, Yarlett N, Griffiths M, Remmers E, Wilder R, Gulko P. The non-major histocompatibility complex quantitative trait locus Cia10 contains a major arthritis gene and regulates disease severity, pannus formation, and joint damage. Arthritis Rheum. 2005;52:322-32.

46. Laragione T, Brenner M, Sherry B, Gulko P. CXCL10 and its receptor CXCR3 regulate synovial fibroblast invasion in rheumatoid arthritis. Arthritis Rheum. 2011;63:3274-83.

47. Nanki T, Nagasaka K, Hayashida K, Saita Y, Miyasaka N. Chemokines regulate IL-6 and IL-8 production by fibroblast-like synoviocytes from patients with rheumatoid arthritis. J Immunol. 2001;167:5381-5.

48. Sawai H, Park YW, Roberson J, Imai T, Goronzy J, Weyand C. T cell costimulation by fractalkine-expressing synoviocytes in rheumatoid arthritis. Arthritis Rheum. 2005;52:1392-401.

49. Toyoda Y, Tabata S, Kishi J, Kuramoto T, Mitsuhashi A, Saijo A, Kawano H, Goto $\mathrm{H}$, Aono $Y$, Hanibuchi M, et al. Thymidine phosphorylase regulates the 
expression of CXCL10 in rheumatoid arthritis fibroblast-like synoviocytes. Arthritis Rheumatol. 2014;66:560-8.

50. Dustin $\mathrm{M}$, Groves J. Receptor signaling clusters in the immune synapse. Annu Rev Biophys. 2012:41:543-56.

51. Bromley S, Burack W, Johnson K, Somersalo K, Sims T, Sumen C, Davis M Shaw A, Allen P, Dustin M. The immunological synapse. Annu Rev Immunol. 2001;19:375-96.

52. Koshy S, Huq R, Tanner M, Atik M, Porter P, Khan F, Pennington M, Hanania N, Corry D, Beeton C. Blocking Kv1.3 channels inhibits Th2 lymphocyte function and treats a rat model of asthma. J Biol Chem. 2014;289:12623-32.

53. Alvaro-Gracia J, Zvaifler N, Firestein G. Cytokines in chronic inflammatory arthritis: V. Mutual antagonism between interferon- $\gamma$ and tumor necrosis factor-a on HLA-DR expression, proliferation, collagenase production, and granulocyte macrophage colony-stimulating factor production by rheumatoid arthritis synoviocytes. J Clin Invest. 1990;86:1790-8.

54. Hashizume M, Hayakawa N, Mihara M. IL-6 trans-signalling directly induces RANKL on fibroblast-like synovial cells and is involved in RANKL induction by TNF-a and IL-17. Rheumatology (Oxford). 2008;47:1635-40.

55. Page C, Smale S, Carty S, Amos N, Lauder S, Goodfellow R, Richards P, Jones S, Topley N, Williams A. Interferon- $\gamma$ inhibits interleukin-1 $\beta$-induced matrix metalloproteinase production by synovial fibroblasts and protects articular cartilage in early arthritis. Arthritis Res Ther. 2010;12:R49.

56. Vermeire $K$, Heremans $H$, Vandeputte $M$, Huang $S$, Billiau A, Matthys $P$. Accelerated collagen-induced arthritis in IFN- $\gamma$ receptor-deficient mice. J Immunol. 1997;158:5507-13.

57. Lee J, Lee J, Park M, Lim M, Park E, Kim E, Yang E, Lee S, Jhun J, Park S, et al. Interferon $\gamma$ suppresses collagen-induced arthritis by regulation of Th17 through the induction of indoleamine-2,3-deoxygenase. PLoS One. 2013;8: e60900.

58. Cannon G, Pincus S, Emkey R, Denes A, Cohen S, Wolfe F, Saway P, Jaffer A, Weaver A, Crogen L, et al. Double-blind trial of recombinant $\gamma$-interferon versus placebo in the treatment of rheumatoid arthritis. Arthritis Rheum. 1989:32:964-73.

59. Machold K, Neumann K, Smolen J. Recombinant human interferon $\gamma$ in the treatment of rheumatoid arthritis: double blind placebo controlled study. Ann Rheum Dis. 1992;51:1039-43.

60. Veys E, Menkes C, Emery P. A randomized, double-blind study comparing twenty-four-week treatment with recombinant interferon- $\gamma$ versus placebo in the treatment of rheumatoid arthritis. Arthritis Rheum. 1997:40:62-8

61. Dolhain R, ter Haar N, Hoefakker S, Tak P, de Ley M, Claassen E, Breedveld F, Miltenburg A. Increased expression of interferon (IFN)- $\gamma$ together with IFN- $\gamma$ receptor in the rheumatoid synovial membrane compared with synovium of patients with osteoarthritis. Br J Rheumatol. 1996;35:24-32.

62. Yuan J, Wegenka U, Lutticken C, Buschmann J, Decker T, Schindler C, Heinrich P, Horn F. The signalling pathways of interleukin- 6 and $y$ interferon converge by the activation of different transcription factors which bind to common responsive DNA elements. Mol Cell Biol. 1994;14:1657-68.

63. Nanki T, Imai T, Kawai S. Fractalkine/CXCL1 in rheumatoid arthritis. Mod Rheumatol. 2017;27:392-7.

64. Nanki T, Urasaki Y, Imai T, Nishimura M, Muramoto K, Kubota T, Miyasaka N. Inhibition of fractalkine ameliorates murine collagen-induced arthritis. J Immunol. 2004;173:7010-6.

65. Pavkova Goldbergova M, Lipkova J, Pavek N, Gatterova J, Vasku A, Soucek $M$, Nemec P. RANTES, MCP-1 chemokines and factors describing rheumatoid arthritis. Mol Immunol. 2012;52:273-8.

66. Shahrara S, Proudfoot A, Woods J, Ruth J, Amin M, Park C, Haas C, Pope R, Haines $G$, Zha Y, et al. Amelioration of rat adjuvant-induced arthritis by MetRANTES. Arthritis Rheum. 2005;52:1907-19.

67. Tian G, Liang J, Wang Z, Zhou D. Emerging role of leptin in rheumatoid arthritis. Clin Exp Immunol. 2014;177:557-70.

68. Carvalheiro H, da Silva J, Souto-Carneiro M. Potential roles of $\mathrm{CD}^{+} \mathrm{T}$ cells in rheumatoid arthritis. Autoimmun Rev. 2013;12:401-9.

69. Tolboom T, van der Helm-Van Mil A, Nelissen R, Breedveld F, Toes R, Huizinga T. Invasiveness of fibroblast-like synoviocytes is an individual patient characteristic associated with the rate of joint destruction in patients with rheumatoid arthritis. Arthritis Rheum. 2005;52:1999-2002.

70. Laragione T, Cheng K, Tanner M, He M, Beeton C, Al-Abed Y, Gulko P. The cation channel Trpv2 is a new suppressor of arthritis severity, joint damage, and synovial fibroblast invasion. Clin Immunol. 2015;158:183-92.

\section{Ready to submit your research? Choose BMC and benefit from:}

- fast, convenient online submission

- thorough peer review by experienced researchers in your field

- rapid publication on acceptance

- support for research data, including large and complex data types

- gold Open Access which fosters wider collaboration and increased citations

- maximum visibility for your research: over $100 \mathrm{M}$ website views per year

At BMC, research is always in progress.

Learn more biomedcentral.com/submissions 